\title{
GEOQUÍMICA E PROVENIÊNCIA DOS SEDIMENTOS DA FORMAÇÃO CORUMBATAÍ NA REGIÃO DE RIO CLARO/SP
}

\author{
Antenor ZANARDO' ${ }^{1}$; Guillermo Rafael Beltran NAVARRO'; ${ }^{1}$ Cibele Carolina \\ MONTIBELLER ${ }^{2}$; Rogers Raphael da ROCHA ${ }^{3}$; Maria Margarita Torres MORENO'; \\ Carolina DEL ROVERI ${ }^{4}$; Andrezza de Almeida AZZI ${ }^{2}$
}

\begin{abstract}
(1) Universidade Estadual Paulista "Júlio de Mesquita Filho" - UNESP/Instituto de Geociências e Ciências Exatas (IGCE)/Departamento de Petrologia e Metalogenia (DPM. Avenida 24-A, n 1515 - 13506-900 - Rio Claro - SP - Caixa Postal 178. Fones: (19) 3526-9240/9239. Endereços eletrônicos: azanardo@rc.unesp.br, mmoreno@rc.unesp.br, grbnavarro@rc.unesp.br (2) Pós-Graduação em Geociências e Meio Ambiente. Instituto de Geociências e Ciências Exatas (IGCE)/Departamento de Petrologia e Metalogenia (DPM). Avenida 24-A, n 1515 - 13506-900 - Rio Claro - SP - Caixa Postal 178. Endereços eletrônicos: andrezzazzi@gmail.com, cibele.cm@outlook.com
\end{abstract}

(3) Engenheiro de Materiais da indústria cerâmica Rocha Forte e Triunfo. Endereço eletrônico: rogers.rocha@ @ochaforte.com.br (4) Universidade Federal de Alfenas (UNIFAL) - Campus Avançado de Poços de Caldas/Instituto de Ciência e Tecnologia/Núcleo de Engenharia de Minas. Endereço eletrônico: cdroveri@gmail.com

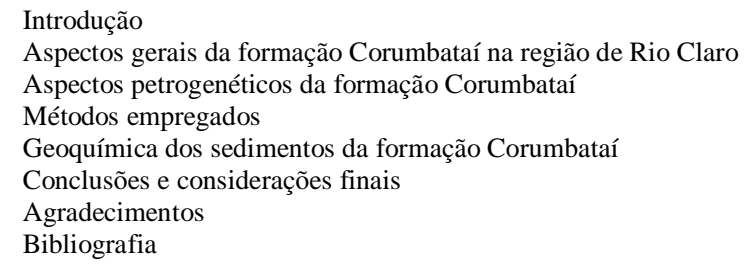

\begin{abstract}
RESUMO - A Formação Corumbataí na região de Rio Claro - Limeira - Araras é representada por uma sucessão de siltitos, constituídos principalmente por filossilicatos (predominando illita, embora também ocorram montmorillonita, biotita, clorita, caulinita e interestratificados regulares e irregulares, quartzo, plagioclásios e feldspatos potássicos, carbonatos, hematita, goethita e zeólitas, de origem autígena e/ou detrítica. Quimicamente as rochas da Formação Corumbataí são classificadas principalmente como wackes e secundariamente como folhelhos, cuja principal fonte são rochas ígneas félsicas e/ou rochas sedimentares quartzosas. A aplicação de índices de maturidade química nas rochas analisadas sugere que estas são quimicamente imaturas e que a fonte foi submetida a condições de intemperismo moderado. Diagramas discriminantes para ambientes tectônicos sugerem que a fonte dos sedimentos da Formação Corumbataí são rochas quimicamente semelhantes a rochas formadas em margem ativa e/ou arcos de ilha, embora depositados em outro contexto geotectônico (bacia intracratônica).

Palavras-chave: Formação Corumbataí, geoquímica, Permiano, Bacia do Paraná.
\end{abstract}

\begin{abstract}
Corumbataí Formation in Rio Claro - Limeira - Araras (São Paulo State, Brazil) is represented by a succession of siltstones mainly consisting of phyllosilicates (predominating illite, although montmorillonite, biotite, chlorite, kaolinite and mixedlayer clay minerals are also present), quartz, feldspars, carbonates, hematite, goethite and zeolites, which may be of authigenic and/or detrital origin. Chemically the rocks of Corumbataí Formation are mainly classified as wackes and secondarily as shales, whose main source are felsic igneous rocks and / or quartzose sedimentary rocks. The application of chemical maturity indexes in the analyzed rocks suggests that these are chemically immature and that the source was subjected to conditions of moderate weathering. Discriminant diagrams for tectonic environments suggest that the source of the Corumbataí Formation sediments are chemically similar to rocks formed in active margin and/or island arcs, although deposited in another geotectonic setting (intracratonic basin). Keywords: Corumbataí Formation, geochemistry, Permian, Paraná Basin.
\end{abstract}

\section{INTRODUÇÃO}

A partir da segunda metade do século XX, diversos autores se dedicaram à geração de padrões geoquímicos de rochas sedimentares (Dypvik, 1979; Bhatia, 1985; Rahman e Faupl, 2003; Rahman e Suzuki, 2007; Hossain et al., 2010; von Eynatten et al., 2012; Jorge et al., 2013 , etc.), apresentando correlações entre o comportamento geoquímico de determinados elementos, as características das áreas fontes, implicações tectônicas e a atuação de processos diagenéticos e intempéricos que deram origem a estes sedimentos (Pettijohn, 1963; Haskin e Frey, 1966; Haskin e Haskin, 1966; McLennan e Taylor, 1980; Taylor e McLennan, 1981; Bhatia, 1983; Bhatia e Crook, 1986; Roser e Korsch, 1988; McLennan et al., 1990; McLennan et al., 1993; Rollinson 1993; Cox et al., 1995; Pearce et al., 1999; Lee, 2009; dentre outros).

A utilização de razões e diagramas discriminantes geoquímicos para rochas sedimentares é uma aplicação já consagrada na literatura internacional (Bhatia 1983; Bhatia e Crook 1986; Cullers, 2000, 2002; ArmstrongAltrin e Verma, 2005; Selvaraj e Chen, 2006; Rahman e Suzuki 2007; Armstrong-Altrin, 
2009; Bakkiaraj et al., 2010; Fu et al., 2010; Etemad-Saeed et al., 2011; Fatima e Khan, 2012; Raza et al., 2012; Moradi et al. 2016; Verma e Armstrong-Altrin, 2016, entre outros), embora alguns aspectos ainda sejam discutidos (Weltje, 2006, 2012; Ryan e Williams, 2007; Pe-Piper et al., 2008; Armstrong-Altrin, 2009; Guo et al., 2011; von Eynatten e Dunkl, 2012; Zaid, 2012, entre outros).

Neste sentido, a Formação Corumbataí (permiano da Bacia do Paraná), que aflora principalmente nos estados de São Paulo, Mato Grosso e Goiás (Figura 1), apresenta lacunas quanto à sua proveniência, desde a natureza das rochas fontes até a efetividade da atuação de mecanismos intempéricos. Diversas pesquisas sobre a Formação Corumbataí foram realizadas a partir da década de 1950, como as de Mendes
(1952), Almeida e Barbosa (1953), Barbosa e Gomes (1958), Landim (1970), Gama Jr. (1979), Petri e Coimbra (1982), Petri e Fulfaro (1983), Souza (1985), Suguio e Souza (1985), Rohn (1994, 1997) e Zanardo et al. (2016), mas todas se utilizaram de métodos petrográficos e de campo, convergindo para interpretações acerca do paleoambiente deposicional desta Formação. Assim, estudos de proveniência dos sedimentos que a compõem, principalmente com a utilização de dados geoquímicos, são escassos, embora seja consenso na literatura internacional que a obtenção de dados geoquímicos acerca de qualquer sequência estudada corresponde a valiosa contribuição para o conhecimento acerca da evolução de bacias sedimentares, fato ainda ignorado no Brasil.

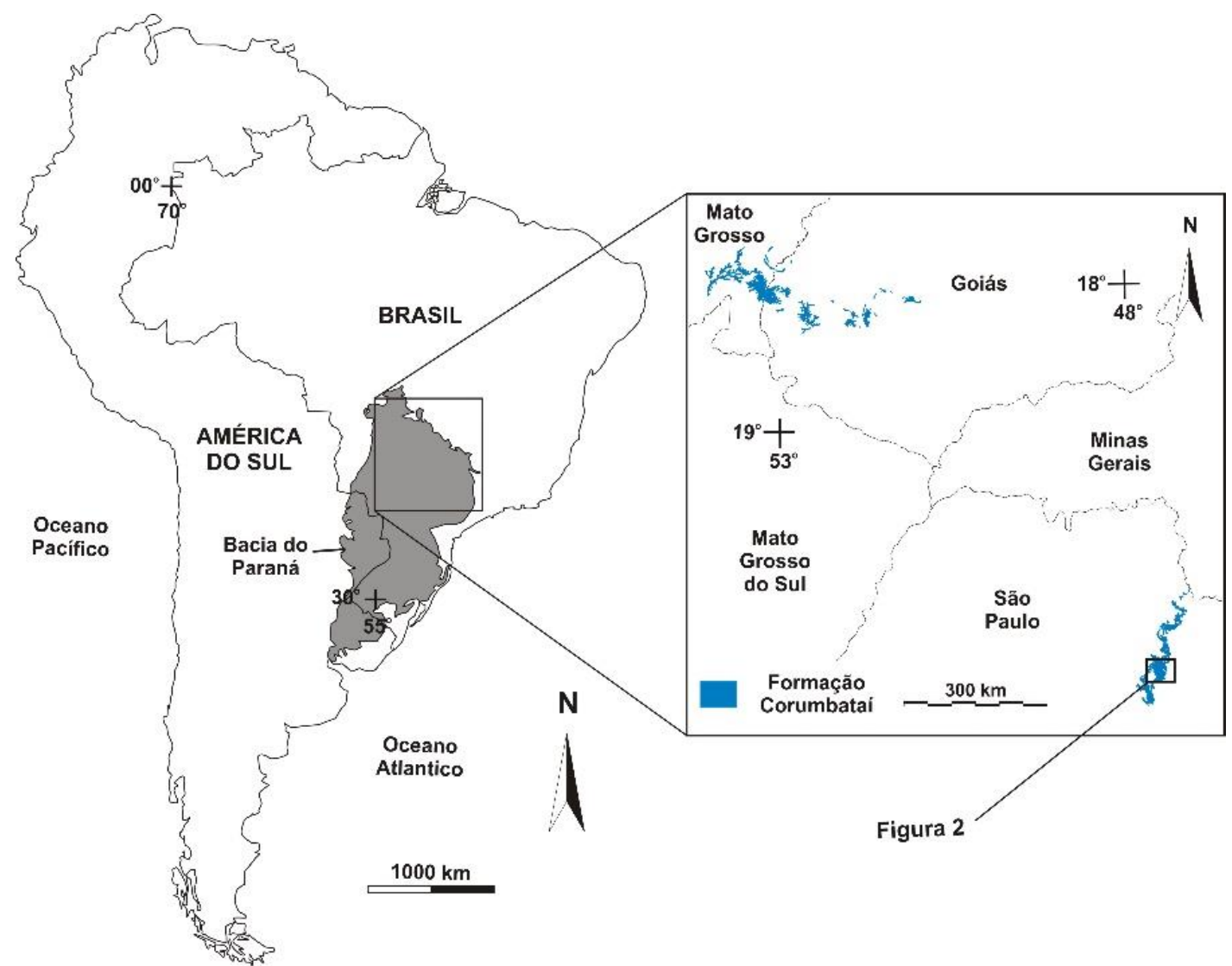

Figura 1. Mapa esquemático da América do Sul, mostrando a localização da Bacia do Paraná (modificado de Hasui et al., 2012) e as regiões onde afloram os sedimentos da Formação Corumbataí (modificado de Lacerda Filho et al, 1999; Lacerda Filho et al., 2004; Perrotta et al., 2005).

Considerando os dados disponíveis atualmente sobre a Formação Corumbataí, e levando em conta as discussões acerca do significado da composição química de sedimentos para análise de proveniência de rochas sedimentares, este artigo visa apresentar dados de elementos maiores e traços da Formação Corumbataí na região de Rio Claro Araras - Limeira (Figura 2), na tentativa de elucidar aspectos referentes à sua proveniência. 


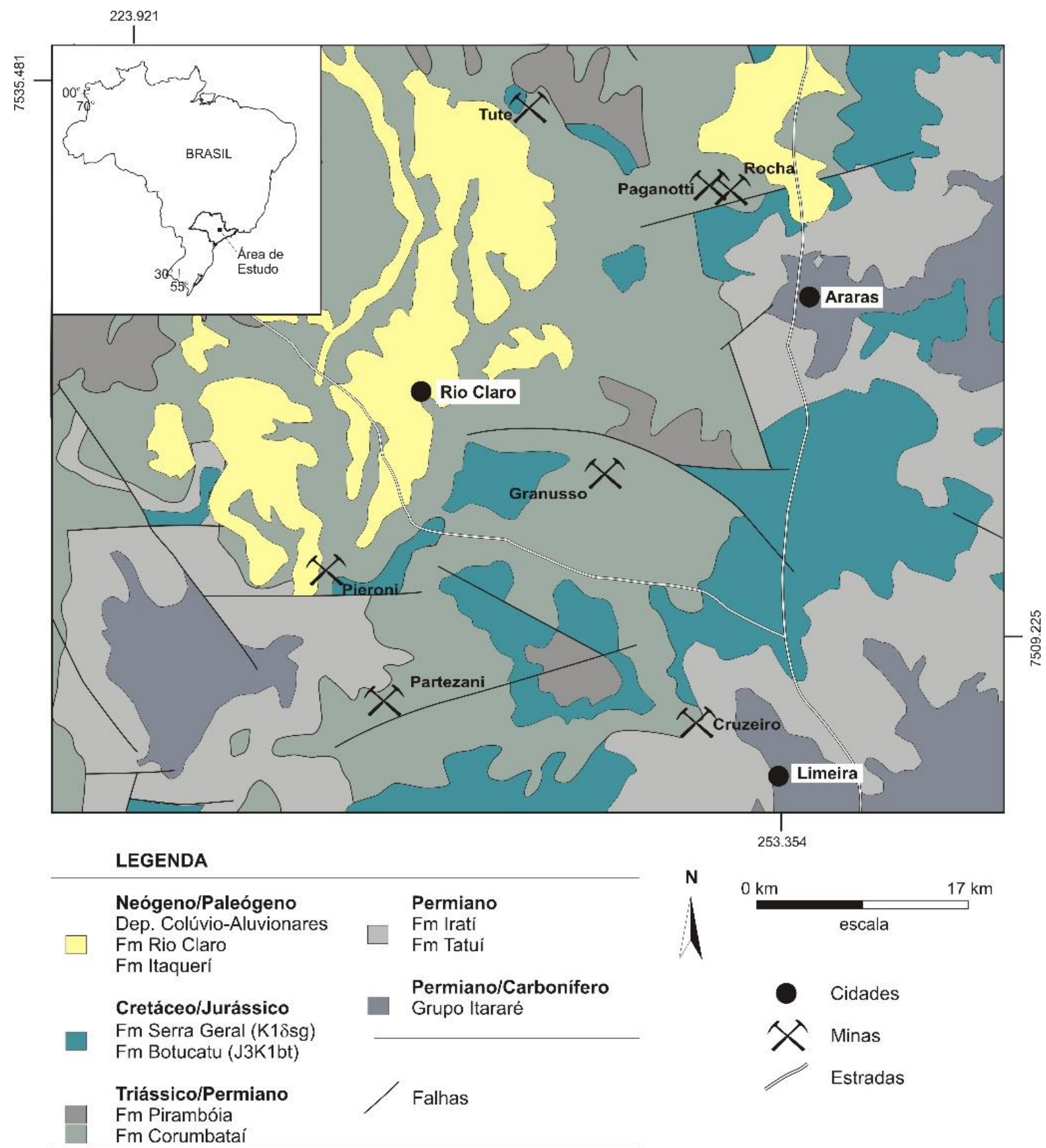

Figura 2. Mapa geológico esquemático mostrando a área de ocorrência da Formação Corumbataí na região de Rio Claro - Limeira - Araras e a localização das lavras de argila da Formação Corumbataí onde as amostras estudadas foram coletadas (modificado de Perrotta et al., 2005).

\section{ASPECTOS GERAIS DA FORMAÇÃO CORUMBATAÍ NA REGIÃO DE RIO CLARO}

Neste trabalho, considera-se que a Formação Corumbataí corresponde ao conjunto de rochas sobreposto à Formação Irati e sotoposto à Formação Piramboia na região do Alto Estrutural de Pitanga (Schneider et al., 1974; Mezzalira et al., 1981; Sousa, 2002), correspondendo em termos estratigráficos à Formação Teresina nos estados do Paraná e de Santa Catarina (Rohn, 1994, 1997; Milani, 2007). Esta unidade, em conjunto com a Formação Irati, compõe o Grupo Passa Dois no domínio paulista da Bacia do Paraná, que integra, juntamente com os grupos Itararé e Guatá, a Supersequência Gondwana I de Milani (1997).

Nas imediações de Rio Claro, a Formação Corumbataí atinge espessura máxima de 130 metros, adelgaçando-se para norte (não ultrapassando $60 \mathrm{~m}$ nas proximidades de Leme e Pirassununga), não chegando a adentrar o estado de Minas Gerais (Landim, 1970; Soares e Landim, 1973). Na região possui contato 
concordante com a Formação Irati (Landim, 1970; Schneider et al., 1974; Sousa, 2002) subjacente e contato predominantemente abrupto com a Formação Piramboia sobrejacente sendo, entretanto, descrita a ocorrência de contato transicional com esta unidade na região do Alto Estrutural de Pitanga (Hachiro, 1996). Em alguns locais, como nos platôs localizados nas proximidades da cidade de Rio Claro, a Formação Corumbataí é diretamente coberta pela Formação Rio Claro, de idade terciária a quaternária, e coberturas correlatas, exibindo contatos nitidamente erosivos (Melo, 1995; Zaine, 2000).

A Formação Corumbataí na área de estudo, corresponde a uma unidade psamo-pelítica, composta predominantemente por siltitos, que podem ser argilosos ou arenosos. Apresenta dominantemente estrutura laminada planoparalela, localmente com laminações cruzadas e onduladas, flaser e gretas de ressecamento. Possui diversas intercalações lenticulares de bone beds/camadas fosfáticas e fossilíferas, de espessuras milimétricas a decimétricas, que podem ser encontradas ao longo de todo o perfil da Formação Corumbataí. Coquinas e níveis de conchas, em geral silicificados, ocorrem apenas na porção superior da unidade (Rohn, 1994).

Com base nas variações texturais e principalmente nas proporções mineralógicas ao longo do empilhamento dos sedimentos da Formação Corumbataí, Zanardo et al. (2016) propõem dividir informalmente esta unidade na região de Rio Claro - Santa Gertrudes em cinco níveis (Figura 3), descritos a seguir.

- nível I: siltito argiloso (illítico/clorítico) cinza e localmente vermelho arroxeado, maciço a bandado, rico em material granular terrígeno e biogênico.

- nível II: siltito argiloso illítico/clorítico cinza a vermelho arroxeado ou marrom chocolate, maciço a sutilmente laminado. Este nível é mais rico em clorita na base do que no topo, e apresenta enriquecimento na proporção de albita para o topo. Localmente apresenta porções cinza na base, passando a domínios variegados em direção ao topo. $\mathrm{O}$ limite superior deste nível é representado por lentes de siltito albítico contendo ankerita/siderita e calcita, às vezes com analcima.

- nível III: siltito argiloso illítico de cor vermelha a arroxeada com intercalações de siltito albítico carbonático de cor creme, de siltito argiloso albítico illítico, carbonático ou não, de cor vermelha, lentes de siltito arenoso albítico illítico carbonático de cor vermelha e de siltito arenoso albítico carbonático de cor creme, com marcas onduladas e laminações cruzadas.

- nível IV: siltito argiloso illítico de cor vermelho tijolo a vermelho arroxeado com intercalações de siltito albítico carbonático e siltito argiloso albítico illítico, carbonático ou não, de cor variando de vermelho tijolo, creme a creme esverdeado. Estas intercalações possuem espessura métrica a decimétrica, e apresentam localmente gretas de ressecamento, laminações cruzadas e onduladas. O topo do nível IV é limitado por leitos descontínuos de calcário impuro com textura poiquilotópica.

- nível V: intercalações de siltito argiloso illítico, carbonático ou não, de espessura decimétrica a métrica, com siltito carbonático albítico de espessura centimétrica a métrica, com gretas de ressecamento e laminações cruzadas. Na base deste pacote, ocorre nível rico em diques clásticos, enquanto no topo deste nível são encontrados leitos e camadas de conchas e coquinas silicificadas.

As espessuras e a continuidade destes níveis não são constantes ao longo da Formação Corumbataí. Alguns estratos podem ser detectados em várias minas separadas por dezenas de quilômetros, porém não aparecem em outras que expõem a mesma porção da coluna estratigráfica (Zanardo et al., 2016). Além disso, a Formação Corumbataí foi afetada por efeito termal associado à intrusão de rochas básicas da Formação Serra Geral, sendo, portanto, constantemente encontrados diques e sills de diabásio, lentes e vênulas de quartzo e de carbonatos, níveis albitizados e zeolíticos distribuídos ao longo de toda a sucessão da formação na região do Alto Estrutural de Pitanga (Zanardo et al., 2016). 

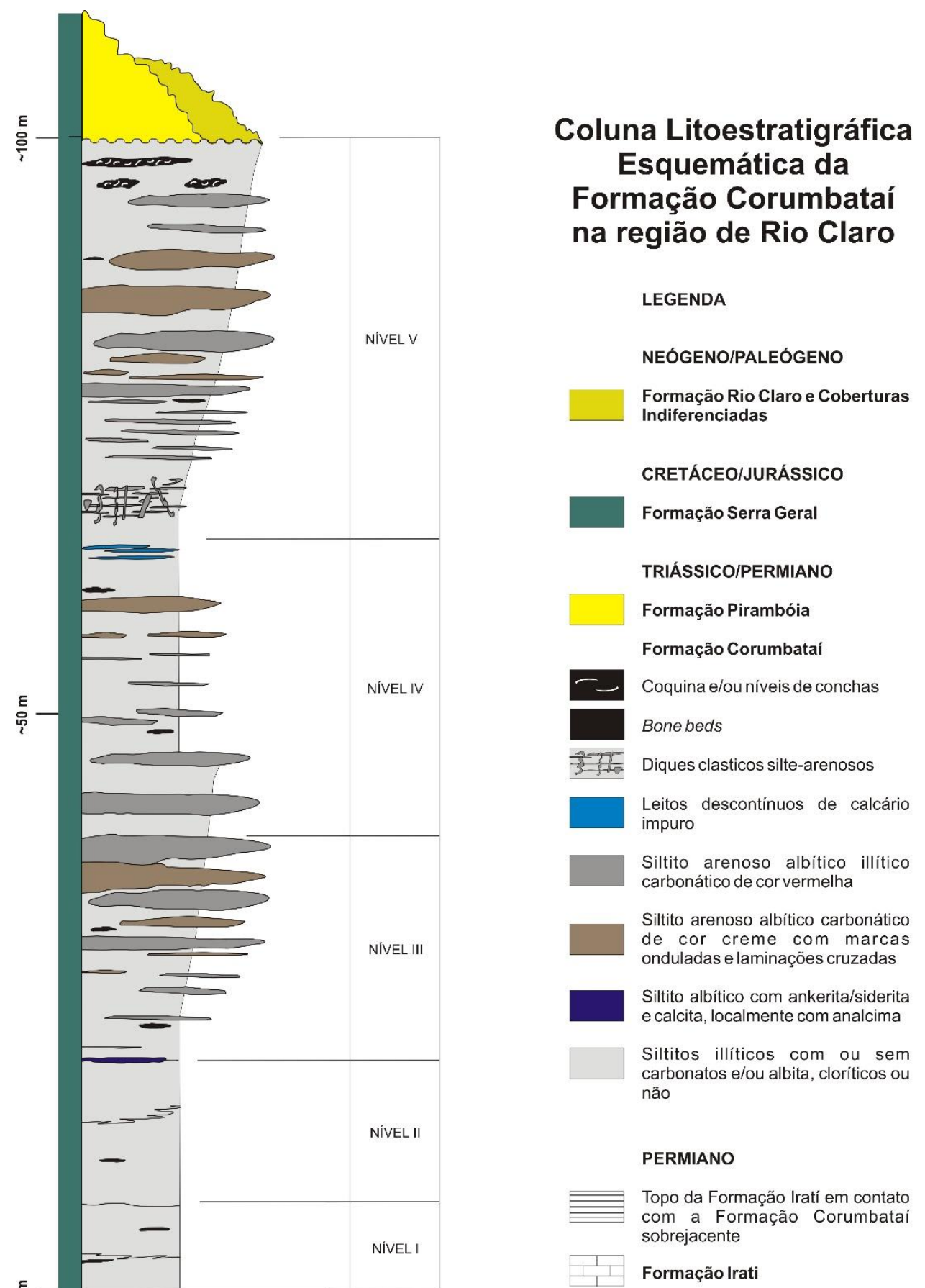

Figura 3. Representação esquemática do empilhamento estratigráfico da Formação Corumbataí na região de Rio Claro - Limeira - Araras. Modificado de Zanardo et al., (2016).

\section{ASPECTOS PETROGENÉTICOS DA FORMAÇÃO CORUMBATAí}

Os estudos petrográficos mostraram que toda a sucessão sedimentar da Formação Corumbataí é predominantemente illítica com proporções variadas de outros filossilicatos (clorita, sericita/muscovita, biotita, caulinita e montmorillonita), de acordo com a posição na coluna estratigráfica. Os filossilicatos perfazem em média cerca de $50 \%$ da composição dos siltitos, sendo que montmorillonita somente aparece como constituinte essencial nos níveis alterados nas porções de topo de algumas jazidas, e a caulinita está presente exclusivamente nos níveis mais alterados (Zanardo et al., 2016). Como constituintes dos 
siltitos, também ocorrem quartzo (em média inferior a 30\%), feldspatos (predominando albita diagenética, com média ao redor de $25 \%$ ) e carbonatos (que ocorrem como mineral essencial apenas nos estratos da parte superior coluna estratigráfica e em veios) (Zanardo et al., 2016). A hematita corresponde em média 5 a $6 \%$ da composição dos níveis mais argilosos e nos níveis sílticos arenosos, de tonalidades mais claras, chega a representar menos de $2 \%$ da rocha. Como minerais acessórios ocorrem turmalina, zircão, rutilo, magnetita, ilmenita, leucoxênio e apatita.

A Formação Corumbataí, com base na distribuição dos litotipos associada à estrutura, textura e composição mineralógica, é interpretada como sendo depositada em um extenso mar epicontinental raso com ligação com o oceano (Schneider et al., 1974; Petri e Coimbra, 1982, entre outros), com indícios de exposições aéreas (presença de grânulos de argila arredondados, interpretados como fragmentos gerados por ressecamento retrabalhados) já nos estratos basais (Zanardo et al., 2016). A evaporação deveria ser bem maior que o aporte de água doce, bem como da velocidade de homogeneização salina caso realmente existisse ligação direta com o oceano, aspecto que poderia ser possibilitado pela existência de extensa plataforma rasa com ondulações leves, resultando na presença de ilhas isoladas, na dependência da maré alta ou baixa, resultando em exposição subaérea, e possibilitando a deposição de sais nos sedimentos da Formação Corumbataí (Zanardo et al., 2016). Neste contexto, as marés mais altas e as grandes tempestades provocariam a homogeneização rápida da salinidade $\mathrm{e}$ dissolução total e parcial dos sais depositados, além de formar os bone beds (Zanardo et al., 2016).

Dessa forma, pode-se interpretar que a deposição ocorreu sob a ação de marés, em meio aquoso salino a hipersalino, com provável deposição química de carbonatos, sulfatos, sais de sódio, potássio e magnésio na porção intermediária a superior da coluna estratigráfica (Zanardo et al., 2016). Os dados petrográficos em associação com as estruturas evidenciam que a coluna de água era maior no início da deposição e foi diminuindo progressivamente para o topo, ao mesmo tempo em que a salinidade aumentava (Zanardo et al., 2016). Cerca de 20 metros acima do contato com a formação Irati já aparecem litotipos ricos em albita neoformada, sugerindo a presença significativa de sais ricos em sódio (como a halita) no sedimento depositado (a formação de albita deve ser possibilitada pela presença de sódio no perfil, uma vez que o efeito hidrotermal gerado pelas intrusões básicas não justifica a presença deste elemento em quantidade suficiente para gerar níveis albitizados, com as continuidades e homogeneidades observadas) (Zanardo et al., 2016).

\section{MÉTODOS EMPREGADOS}

Foram selecionadas 38 amostras frescas e representativas de toda a coluna estratigráfica da Formação Corumbataí (21 amostras da base, 4 amostras da porção intermediária e 13 amostras do topo da sucessão litológica) para estudos litogeoquímicos de elementos maiores, menores, traços e terras raras (ETR). A localização das minas onde as amostras foram coletadas é mostrada na figura 2. As análises químicas (rocha total) foram realizadas pelo Laboratório Acme (Analytical Laboratories LTD, Vancouver, Canadá). Os elementos maiores $\left(\mathrm{SiO}_{2}, \mathrm{TiO}_{2}, \mathrm{Al}_{2} \mathrm{O}_{3}, \mathrm{Fe}_{2} \mathrm{O}_{3} \mathrm{~T}, \mathrm{MnO}\right.$, $\mathrm{MgO}, \mathrm{CaO}, \mathrm{Na}_{2} \mathrm{O}, \mathrm{K}_{2} \mathrm{O}, \mathrm{P}_{2} \mathrm{O}_{5}$ e também $\mathrm{Cr}_{2} \mathrm{O}_{3}$ ) foram obtidos por Espectrometria de Emissão em Plasma Indutivamente Acoplado (ICP-
OES), após fusão utilizando metaborato/tetraborato de lítio e digestão em ácido nítrico diluído, sendo a perda ao fogo (LOI - loss on ignition) determinada pela diferença de peso da amostra antes e depois do aquecimento a $1000^{\circ} \mathrm{C}$ por quatro horas. Os elementos traços $(\mathrm{Cs}, \mathrm{Rb}, \mathrm{Ba}, \mathrm{Th}, \mathrm{U}, \mathrm{Nb}, \mathrm{Ta}$, $\mathrm{Sr}, \mathrm{Zr}, \mathrm{Hf}, \mathrm{Y}, \mathrm{Sc}, \mathrm{V}, \mathrm{Co}, \mathrm{Ga})$ e terras raras (La, $\mathrm{Ce}, \mathrm{Pr}, \mathrm{Nd}, \mathrm{Sm}, \mathrm{Eu}, \mathrm{Gd}, \mathrm{Tb}, \mathrm{Dy}, \mathrm{Ho}, \mathrm{Er}, \mathrm{Tm}$, $\mathrm{Yb}, \mathrm{Lu}$ ) foram analisados por Espectrometria de Massa com Plasma Indutivamente Acoplado (ICP-MS), após fusão utilizando metaborato/tetraborato de lítio e digestão em ácido nítrico, sendo que para os metais $\mathrm{Cu}, \mathrm{Ni}$, $\mathrm{Pb}$ e $\mathrm{Zn}$ a digestão foi por água régia. $\mathrm{O}$ tratamento dos dados geoquímicos e a 
construção de diagramas foram realizados com o emprego dos programas MINPET versão 2.02 (Richard, 1995) e PETROGRAPH versão 2 beta dic2007 (Petrelli et al., 2005). Os resultados das análises químicas são mostrados na tabela 1 .

Tabela 1. Análises químicas representativas de sedimentos da Formação Corumbataí na região de Rio Claro - SP.

\begin{tabular}{|c|c|c|c|c|c|c|c|c|c|c|c|}
\hline Amostra & 11 & 12 & 13 & 14 & 15 & 20 & 21 & 22 & 23 & 24 & 25 \\
\hline $\mathrm{SiO}_{2}$ & 65,75 & 63,07 & 62,1 & 61,34 & 60,11 & 62,41 & 63,22 & 68,7 & 66,96 & 66,85 & 66,63 \\
\hline $\mathrm{TiO}_{2}$ & 0,62 & 0,63 & 0,65 & 0,45 & 0,66 & 0,53 & 0,57 & 0,49 & 0,6 & 0,58 & 0,61 \\
\hline $\mathrm{Al}_{2} \mathrm{O}_{3}$ & 14,76 & 15,65 & 15,58 & 11,3 & 16,17 & 12,66 & 13,48 & 12,39 & 13,92 & 13,77 & 14,19 \\
\hline $\mathrm{Fe}_{2} \mathrm{O}_{3}$ & 5,86 & 5,55 & 5,47 & 3,95 & 5,61 & 3,7 & 4,82 & 3,07 & 5,3 & 5,45 & 5,35 \\
\hline $\mathrm{MnO}$ & 0,04 & 0,05 & 0,05 & 0,11 & 0,06 & 0,12 & 0,1 & 0,07 & 0,06 & 0,04 & 0,05 \\
\hline $\mathrm{MgO}$ & 1,97 & 2,16 & 2,35 & 2,06 & 2,38 & 3,49 & 2,39 & 2,17 & 2,01 & 2,03 & 1,91 \\
\hline $\mathrm{CaO}$ & 0,6 & 0,28 & 0,28 & 5,84 & 0,27 & 3,94 & 3,04 & 1,95 & 1,01 & 0,73 & 0,62 \\
\hline $\mathrm{Na}_{2} \mathrm{O}$ & 1,14 & 0,14 & 0,08 & 1,39 & 0,1 & 4,5 & 3,52 & 4,82 & 2,98 & 2,4 & 2,42 \\
\hline $\mathrm{K}_{2} \mathrm{O}$ & 3,59 & 3,67 & 3,56 & 2,7 & 3,44 & 2,17 & 3,17 & 1,62 & 3,47 & 3,63 & 3,54 \\
\hline $\mathrm{P}_{2} \mathrm{O}_{5}$ & 0,18 & 0,07 & 0,07 & 0,15 & 0,1 & 0,14 & 0,14 & 0,16 & 0,24 & 0,26 & 0,17 \\
\hline LOI & 5,3 & 8,5 & 9,6 & 10,4 & 10,9 & 6,1 & 5,3 & 4,4 & 3,2 & 4,1 & 4,3 \\
\hline Total & 99,81 & 99,77 & 99,79 & 99,69 & 99,8 & 99,76 & 99,75 & 99,84 & 99,75 & 99,84 & 99,79 \\
\hline Sc & 13 & 13 & 13 & 11 & 13 & 9 & 11 & 9 & 13 & 13 & 13 \\
\hline V & 81 & 80 & 87 & 73 & 94 & 62 & 80 & 49 & 77 & 90 & 80 \\
\hline $\mathrm{Cr}$ & 34,21 & 47,89 & 75,26 & 54,74 & 75,26 & 47,89 & 109,47 & 27,37 & 54,74 & 47,89 & 54,74 \\
\hline Co & 12 & 11,9 & 8,5 & 8,7 & 14,1 & 8 & 9,1 & 6,9 & 11,9 & 11,1 & 11,5 \\
\hline $\mathrm{Ni}$ & 19,9 & 18,5 & 15,4 & 15,4 & 15,3 & 12,6 & 18,5 & 11,2 & 21,7 & 25,1 & 23 \\
\hline $\mathrm{Cu}$ & 17,4 & 14 & 15,6 & 21,6 & 26,1 & 14,6 & 8,6 & 14,6 & 21,9 & 30,2 & 27,2 \\
\hline $\mathrm{Zn}$ & 73 & 82 & 81 & 46 & 77 & 68 & 64 & 49 & 72 & 79 & 78 \\
\hline $\mathrm{Rb}$ & 179,4 & 234,4 & 220 & 130,3 & 203 & 87 & 171 & 59,2 & 206,8 & 202,6 & 203,9 \\
\hline $\mathrm{Cs}$ & 8 & 11,1 & 12,5 & 7,6 & 11,6 & 2,5 & 9,7 & 1,7 & 9,9 & 8 & 9,1 \\
\hline $\mathrm{Sr}$ & 178,6 & 92,1 & 86 & 297,4 & 79 & 163,8 & 194,1 & 129,9 & 205,4 & 181,1 & 159,9 \\
\hline $\mathrm{Ba}$ & 473 & 752 & 642 & 1451 & 576 & 575 & 488 & 579 & 491 & 412 & 464 \\
\hline $\mathrm{Y}$ & 21,7 & 26,8 & 39,6 & 19,5 & 35,5 & 20,9 & 21,8 & 24,2 & 24,3 & 23,7 & 22,1 \\
\hline $\mathrm{Zr}$ & 134,1 & 162,6 & 164,1 & 128,4 & 147,4 & 151,9 & 148,7 & 205,9 & 146,2 & 136,6 & 139,6 \\
\hline Hf & 4,4 & 4,8 & 5,1 & 4,4 & 4,6 & 4,2 & 4,6 & 6,3 & 4,3 & 4,3 & 4,2 \\
\hline $\mathrm{Nb}$ & 12,4 & 14,6 & 14,1 & 10,3 & 14,1 & 11,4 & 12 & 11,6 & 13,6 & 12,5 & 13,9 \\
\hline $\mathrm{Ta}$ & 1 & 1,1 & 1,1 & 0,7 & 1,1 & 0,8 & 0,9 & 0,9 & 1 & 0,9 & 0,9 \\
\hline $\mathrm{Pb}$ & 22,6 & 15 & 14,1 & 17,9 & 15,4 & 12,6 & 17,1 & 19,4 & 20,5 & 17,9 & 19,5 \\
\hline Th & 14,1 & 14,9 & 16,3 & 9,5 & 17,8 & 11,7 & 14 & 12 & 13,9 & 11,8 & 12,3 \\
\hline $\mathrm{U}$ & 2,5 & 2,4 & 2,3 & 4,4 & 3,5 & 2,2 & 2,3 & 2,7 & 2,1 & 2,1 & 2,2 \\
\hline $\mathrm{Ga}$ & 18,4 & 19,8 & 18,9 & 13,7 & 18,8 & 16,2 & 15,3 & 13 & 17,1 & 16,3 & 17,4 \\
\hline $\mathrm{La}$ & 31,2 & 36,4 & 44,9 & 28 & 61,7 & 28,1 & 28,6 & 32,6 & 31,6 & 28,5 & 30,7 \\
\hline $\mathrm{Ce}$ & 65,1 & 74,1 & 89 & 58,7 & 110,4 & 61,3 & 62,8 & 68,9 & 65,5 & 58 & 64 \\
\hline $\operatorname{Pr}$ & 7,48 & 9,59 & 12,62 & 6,67 & 14,85 & 6,79 & 7,09 & 7,83 & 7,47 & 6,77 & 7,29 \\
\hline $\mathrm{Nd}$ & 28,3 & 39,7 & 53,8 & 25,7 & 55,6 & 24 & 27,5 & 30 & 27,2 & 25,3 & 27,3 \\
\hline $\mathrm{Sm}$ & 5,57 & 6,97 & 9,83 & 4,4 & 9,45 & 4,69 & 4,94 & 5,22 & 5,12 & 4,89 & 5,03 \\
\hline $\mathrm{Eu}$ & 1,03 & 1,42 & 1,92 & 0,84 & 1,83 & 0,88 & 0,91 & 1,05 & 0,94 & 0,94 & 1 \\
\hline $\mathrm{Gd}$ & 4,79 & 6,34 & 8,46 & 3,66 & 7,21 & 3,95 & 4,11 & 4,32 & 4,2 & 3,88 & 4,14 \\
\hline $\mathrm{Tb}$ & 0,77 & 0,96 & 1,37 & 0,61 & 1,16 & 0,65 & 0,69 & 0,74 & 0,73 & 0,7 & 0,71 \\
\hline Dy & 4,24 & 5,06 & 7,38 & 3,47 & 6,57 & 3,61 & 3,88 & 4 & 4,01 & 3,87 & 3,67 \\
\hline Ho & 0,86 & 1,02 & 1,39 & 0,66 & 1,17 & 0,72 & 0,74 & 0,84 & 0,84 & 0,77 & 0,75 \\
\hline $\mathrm{Er}$ & 2,49 & 2,77 & 3,87 & 2 & 3,3 & 2,01 & 2,37 & 2,35 & 2,42 & 2,27 & 2,19 \\
\hline $\mathrm{Tm}$ & 0,39 & 0,43 & 0,59 & 0,31 & 0,52 & 0,33 & 0,35 & 0,36 & 0,37 & 0,35 & 0,36 \\
\hline $\mathrm{Yb}$ & 2,42 & 2,84 & 3,66 & 1,78 & 3,01 & 2,22 & 2,17 & 2,41 & 2,39 & 2,25 & 2,06 \\
\hline $\mathrm{Lu}$ & 0,37 & 0,4 & 0,58 & 0,31 & 0,5 & 0,34 & 0,33 & 0,37 & 0,37 & 0,36 & 0,33 \\
\hline
\end{tabular}




\section{GEOQUÍMICA DOS SEDIMENTOS DA FORMAÇÃO CORUMBATAÍ}

$\mathrm{O}$ teor de $\mathrm{SiO}_{2}$ ao longo do perfil dos sedimentos da Formação Corumbataí varia entre 55,32 e 71,13\%. Os teores de $\mathrm{Al}_{2} \mathrm{O}_{3}$, $\mathrm{Fe}_{2} \mathrm{O}_{3} \mathrm{~T}, \mathrm{MgO}$ e $\mathrm{CaO}$ variam de 9,74 a $17,63 \%$, 2,74 a $6,78 \%, 0,4$ a $4,44 \%$ e 0,01 a $6,48 \%$ respectivamente. $\mathrm{O}$ teor de $\mathrm{Na}_{2} \mathrm{O}$ varia entre 0,06 e 4,82\%, o de $\mathrm{K}_{2} \mathrm{O}$ varia entre 1,51 e $3,85 \%$ e o de $\mathrm{TiO}_{2}$ varia de 0,35 a $0,74 \%$. Os teores de $\mathrm{P}_{2} \mathrm{O}_{5}$ e $\mathrm{MnO}$ variam de 0,02 a $0,15 \%$ e de 0,05 a $0,57 \%$ respectivamente.

A distribuição dos elementos maiores em relação à $\mathrm{SiO}_{2}$, e também em relação ao $\mathrm{Al}_{2} \mathrm{O}_{3}$ para as amostras analisadas, não permite diferenciar grupos (Figuras 4 e 5), demonstrando que em relação a estes elementos não existem diferenças ao longo de todo o perfil, sugerindo que todo os sedimentos possuem a mesma fonte, ou que houve homogeneização eficaz das fases minerais provenientes de diversas fontes. Correlações de elementos maiores em relação a $\mathrm{SiO}_{2}$ são pouco expressivas, sendo observada fraca correlação negativa de $\mathrm{CaO}$ com relação ao $\mathrm{SiO}_{2}$ acompanhada de correlação negativa de LOI, como reflexo da presença de carbonatos como componente secundário nas rochas analisadas, além da variação do LOI decorrente da desidratação dos argilominerais na fusão.

Em relação ao $\mathrm{Al}_{2} \mathrm{O}_{3}$, observa-se marcada correlação positiva de $\mathrm{TiO}_{2}$ e $\mathrm{Fe}_{2} \mathrm{O}_{3 \mathrm{~T}}$, e correlação negativa relativamente bem definida do $\mathrm{CaO}$, esta última devido à proporção média de minerais carbonáticos ser maior nas rochas com menor teor de filossilicatos, como constatado em estudos petrográficos. Também $\mathrm{Na}_{2} \mathrm{O}$ e o $\mathrm{K}_{2} \mathrm{O}$ apresentam fracas correlações com $\mathrm{Al}_{2} \mathrm{O}_{3}$, negativa e positiva respectivamente, aspecto congruente com o observado nos estudos petrográfico, uma vez que a albita é muito mais frequente nos estratos mais pobres em filossilicatos. Com relação ao $\mathrm{TiO}_{2}$ e ao $\mathrm{Fe}_{2} \mathrm{O}_{3 \mathrm{~T}}$, a correlação pode indicar que estes elementos se encontram em parte na estrutura dos argilominerais, como relictos da alteração de minerais silicáticos contendo $\mathrm{Ti}^{4+}$ na estrutura (como substituição nas posições tetraédrica ou octaédrica) e, principalmente, pelo maior teor de óxidos e hidróxidos nos níveis mais ricos em filossilicatos.
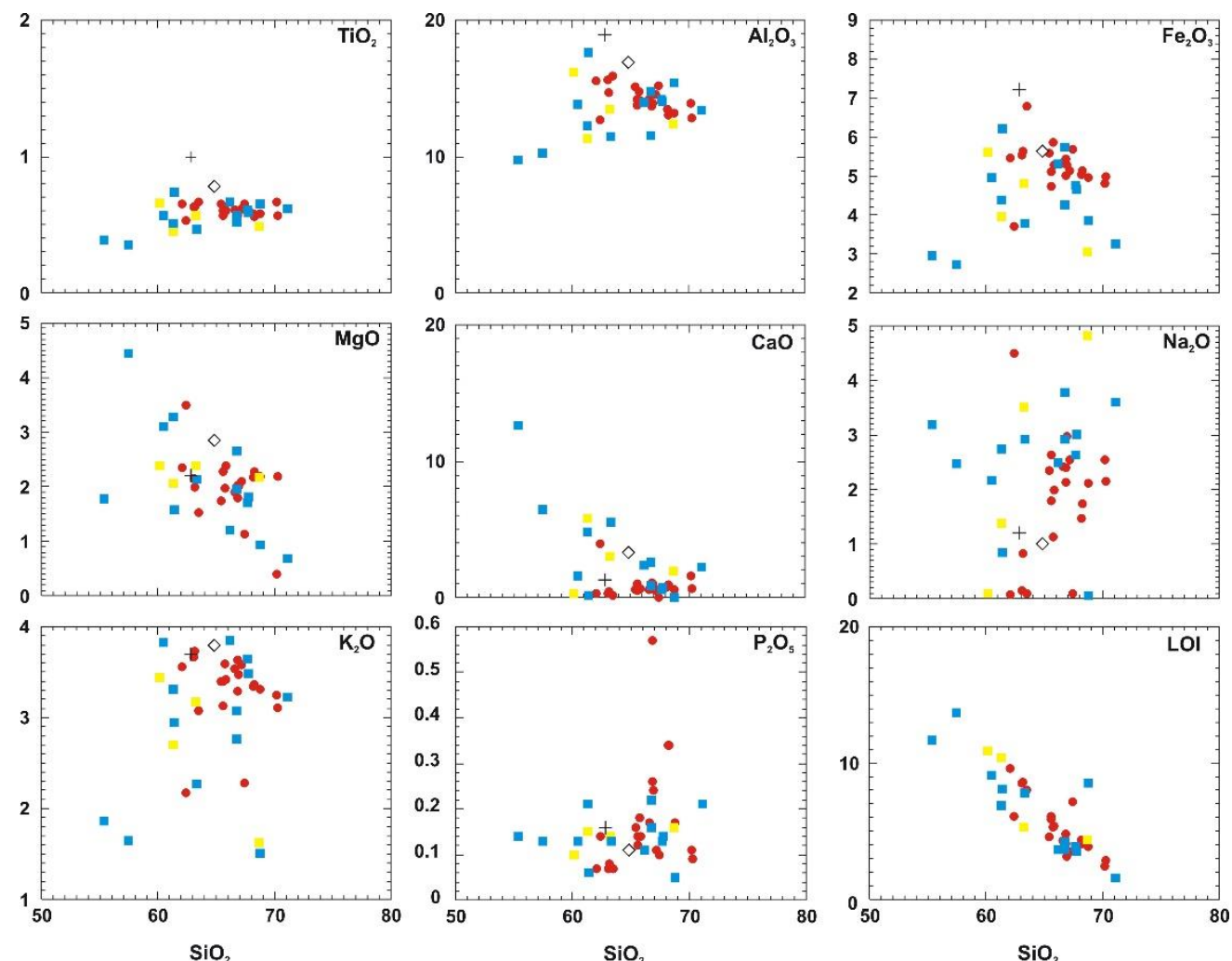

Figura 4. Diagramas binários de elementos maiores versus $\mathrm{SiO}_{2}$, mostrando a variação da composição das amostras estudadas. Cruz: NASC; Losango: PAAS. Círculos vermelhos: amostras da base da Formação Corumbataí; Quadrados amarelos: amostras da porção intermediária da Formação Corumbataí; Quadrados azuis: amostras do topo da Formação Corumbataí. 

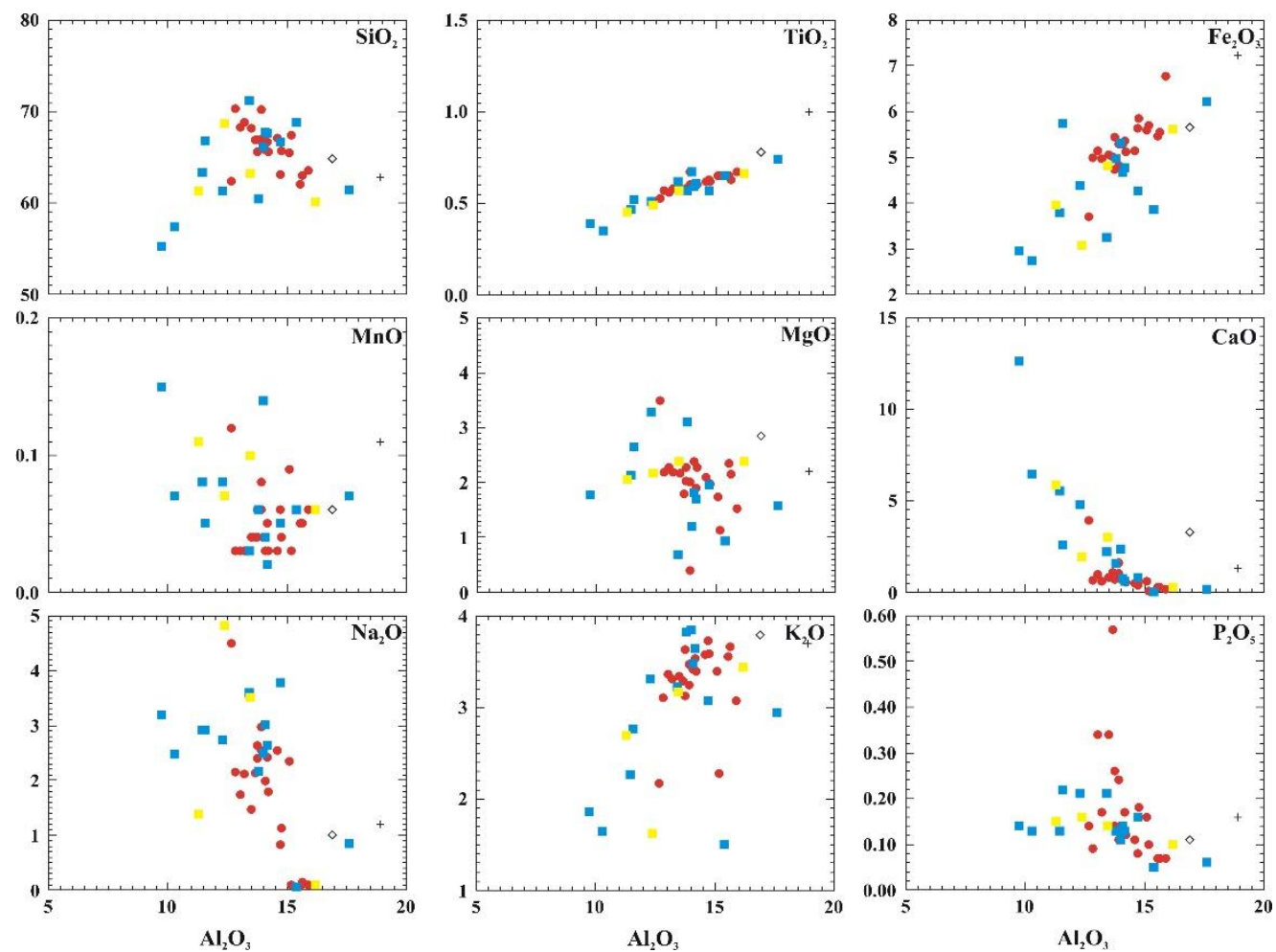

Figura 5. Diagramas binários de elementos maiores versus $\mathrm{Al}_{2} \mathrm{O}_{3}$, mostrando a variação da composição das amostras estudadas. Cruz: NASC; Losango: PAAS. Círculos vermelhos: amostras da base da Formação Corumbataí; Quadrados amarelos: amostras da porção intermediária da Formação Corumbataí; Quadrados azuis: amostras do topo da Formação Corumbataí.

Os teores de elementos menores e traços para todas as amostras analisadas também não apresentam diferenças significativas entre a base, o meio e o topo da Formação Corumbataí, indicando que a natureza da fonte destes sedimentos permaneceu a mesma durante a deposição de todo o pacote analisado (Figura 6). Nos diagramas binários de elementos maiores e traços, as amostras da Formação Corumbataí são comparadas com as médias mundiais para sedimentos NASC (North American Shale Composite, Gromet et al., 1984) e PAAS (Post Archean Average Shale, Taylor e McLennan, 1981). Comparativamente com as médias mundiais os sedimentos da Formação Corumbataí possuem menores teores de $\mathrm{TiO}_{2}, \mathrm{Fe}_{2} \mathrm{O}_{3}$ T e $\mathrm{Al}_{2} \mathrm{O}_{3}$. Os teores de $\mathrm{MgO}$, $\mathrm{CaO}, \mathrm{K}_{2} \mathrm{O}$ e $\mathrm{P}_{2} \mathrm{O}_{5}$ são semelhantes e o teor de $\mathrm{Na}_{2} \mathrm{O}$ é maior. Em relação aos elementos traços, possuem menores teores em $\mathrm{Ni}, \mathrm{Cu}, \mathrm{Cr}$, $\mathrm{Co}, \mathrm{V}, \mathrm{Sc}, \mathrm{Nb}$ e $\mathrm{Zr}$, e possuem teores semelhantes em $\mathrm{Cs}, \mathrm{Ba}, \mathrm{Rb}, \mathrm{Sr}, \mathrm{Zn}, \mathrm{Ga}, \mathrm{Y}, \mathrm{Pb}$, Ta, U e Th.

Herron (1988) propõe uma forma de relacionar a composição química de sedimentos (arenitos e folhelhos terrígenos) com esquemas de classificação de rochas sedimentares já existentes, utilizando para isso as razões $\mathrm{SiO}_{2} / \mathrm{Al}_{2} \mathrm{O}_{3}, \mathrm{Fe}_{2} \mathrm{O}_{3} / \mathrm{K}_{2} \mathrm{O}$ e o conteúdo em $\mathrm{CaO}$. O sistema proposto (SandClass) é iminentemente baseado em uma classificação química, embora, segundo o autor, concorde com os resultados petrográficos em mais de $85 \%$ dos casos analisados. Quimicamente, os sedimentos da Formação Corumbataí são classificados de acordo com o diagrama de Herron (1988) predominantemente como wackes e secundariamente como folhelhos (Figura 7A). Roser e Korsch (1988) propõem o uso de funções discriminantes $(\mathrm{F} 1=$ $30,683 \mathrm{TiO}_{2} / \mathrm{Al}_{2} \mathrm{O}_{3}-12,541 \mathrm{Fe}_{2} \mathrm{O}_{3 \mathrm{~T}} / \mathrm{Al}_{2} \mathrm{O}_{3}+$ $7,329 \mathrm{MgO} / \mathrm{Al}_{2} \mathrm{O}_{3}+12,031 \mathrm{Na}_{2} \mathrm{O} / \mathrm{Al}_{2} \mathrm{O}_{3}+$ $35,402 \mathrm{~K}_{2} \mathrm{O} / \mathrm{Al}_{2} \mathrm{O}_{3}-6,382$ e $\mathrm{F} 2=$ $56,5 \mathrm{TiO}_{2} / \mathrm{Al}_{2} \mathrm{O}_{3}-10,879 \mathrm{Fe}_{2} \mathrm{O}_{3} \mathrm{~T} / \mathrm{Al}_{2} \mathrm{O}_{3}+$ $30,875 \mathrm{MgO} / \mathrm{Al}_{2} \mathrm{O}_{3}-5,404 \mathrm{Na}_{2} \mathrm{O} / \mathrm{Al}_{2} \mathrm{O}_{3}+$ $11,112 \mathrm{~K}_{2} \mathrm{O} / \mathrm{Al}_{2} \mathrm{O}_{3}$ - 3,89) para dividir os campos relativos às diferentes proveniências de rochas sedimentares (rochas fontes: sedimentares quartzosas, intermediárias, félsicas e máficas). Segundo o diagrama de Roser e Korsch (1988), os sedimentos da Formação Corumbataí são predominantemente 

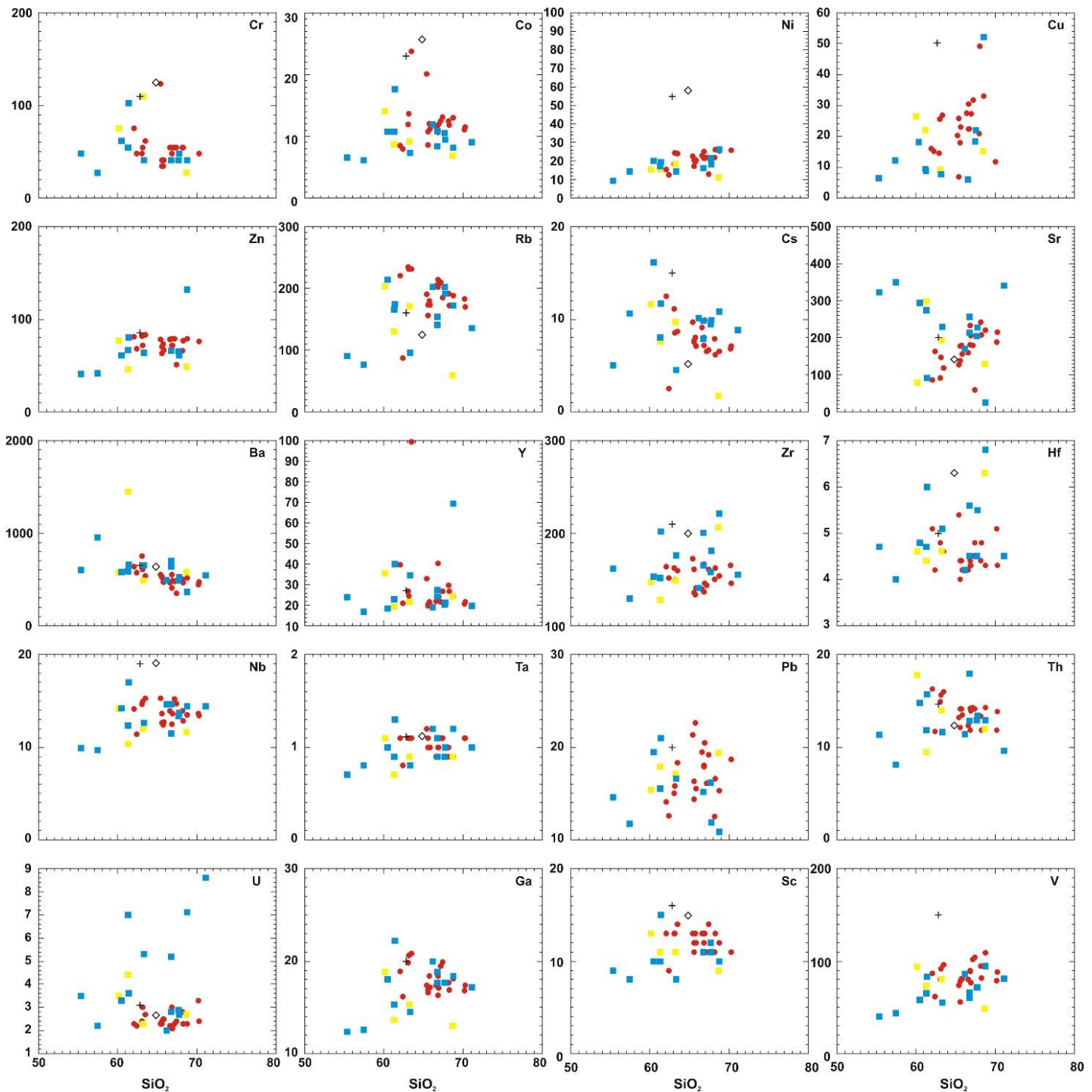

Figura 6. Diagramas binários de elementos menores e traço versus $\mathrm{SiO}_{2}$, mostrando a variação da composição das amostras estudadas. Cruz: NASC; Losango: PAAS. Círculos vermelhos: amostras da base da Formação Corumbataí; Quadrados amarelos: amostras da porção intermediária da Formação Corumbataí; Quadrados azuis: amostras do topo da Formação Corumbataí.
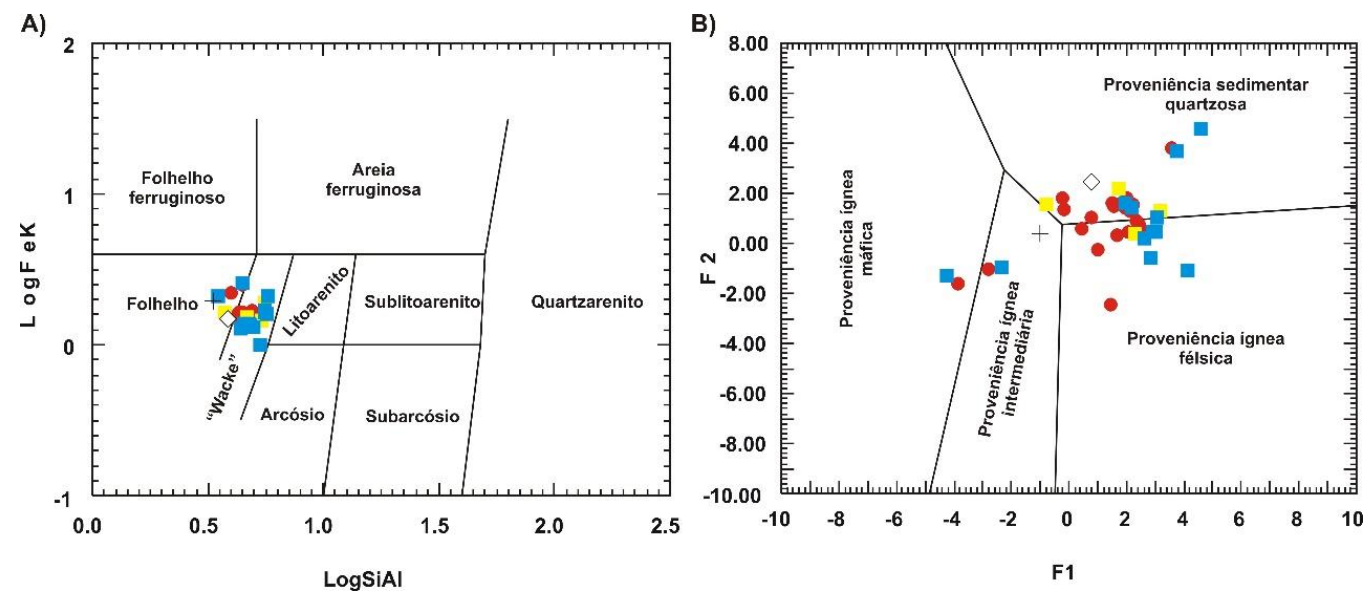

Figura 7. A) Classificação química das amostras analisadas segundo diagrama de Herron (1988). B) Diagrama para rocha fonte das amostras analisadas (diagrama de Roser e Korsch, 1988). Cruz: NASC; Losango: PAAS. Círculos vermelhos: amostras da base da Formação Corumbataí; Quadrados amarelos: amostras da porção intermediária da Formação Corumbataí; Quadrados azuis: amostras do topo da Formação Corumbataí. 
Cox et al. (1995) propõem o uso do Índice de Variação Composicional (Index of Compositional Variability - ICV) e da razão $\mathrm{K}_{2} \mathrm{O} / \mathrm{Al}_{2} \mathrm{O}_{3}$, principalmente para lamitos, para indicar variações na proporção de minerais do grupo dos filossilicatos (grupo das argilas) em relação a minerais não argilosos, que refletem o aporte de sedimentos detríticos, a reciclagem de material sedimentar e o grau de alteração/maturidade química dos sedimentos. O ICV também pode ser utilizado para avaliar a variabilidade geoquímica resultante da seleção hidráulica. A Formação Corumbataí possui valores de ICV entre 0,46 - 2,36 (predominando valores entre 0,65 a 1,77, correspondentes ao intervalo de variação composicional dos plagioclásios e/ou ao campo composicional das illitas derivadas de alteração de filossilicatos), e razões $\mathrm{K}_{2} \mathrm{O} / \mathrm{Al}_{2} \mathrm{O}_{3}$ variando entre 0,09 a 0,27 (predominando valores maiores que 0,19 , correspondentes ao campo composicional dos argilominerais, próximo ao campo composicional das illitas), indicando que as rochas sedimentares analisadas apresentam grau de maturidade variável (Figura 8) e são derivadas de fonte submetida a intemperismo moderado a intenso. A razão $\mathrm{SiO}_{2} / \mathrm{Al}_{2} \mathrm{O}_{3}$ também é utilizada como indicador de maturidade composicional de sedimentos, sendo que valores acima de 10 indicam alto grau de maturidade. A Formação Corumbataí possui razões $\mathrm{SiO}_{2} / \mathrm{Al}_{2} \mathrm{O}_{3}$ variando entre $3,48 \mathrm{e}$ 5,77 (média de 4,77), o que indica baixa maturidade composicional.

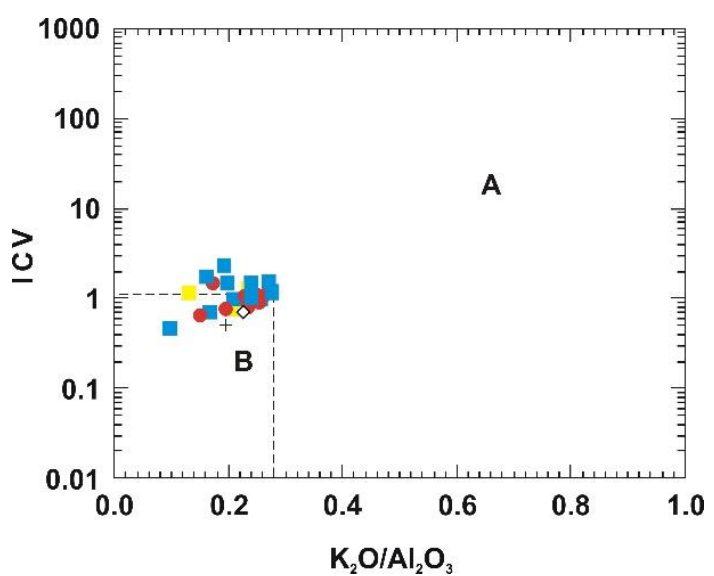

Figura 8. Índice de Variação Composicional (Index of Compositional Variability - ICV) e a razão $\mathrm{K}_{2} \mathrm{O} / \mathrm{Al}_{2} \mathrm{O}_{3}$. Modificado de Cox et al. (1995). A) sedimentos quimicamente imaturos. B) sedimentos quimicamente maturos.

O CIA (Chemical Index of Alteration, Nesbitt e Young, 1982) é utilizado para determinar a intensidade do intemperismo atuante na rocha fonte, sendo que valores elevados $(>70)$ sugerem intemperismo químico intenso. Neste estudo, os valores de $\mathrm{CaO}$ foram corrigidos utilizando o método de McLennan et al. (1993), em que, após a correção dos valores de $\mathrm{CaO}$ para fosfatos, o excedente é aceito como $\mathrm{CaO}^{*}$ apenas se $\mathrm{CaO}<\mathrm{Na}_{2} \mathrm{O}$ na amostra. Quando $\mathrm{CaO}>\mathrm{Na}_{2} \mathrm{O}$, considera-se que o valor de $\mathrm{CaO}^{*}=\mathrm{Na}_{2} \mathrm{O}$. A Formação Corumbataí apresenta valores de CIA entre 54,17 e 90,68 (média de 68,83), predominando valores abaixo de 70, ligeiramente maiores que o valor de CIA do NASC (CIA 58), o que também sugere moderado intemperismo químico na fonte. A razão $\mathrm{Al}_{2} \mathrm{O}_{3} / \mathrm{Na}_{2} \mathrm{O}$ também é utilizada para determinar a intensidade de intemperismo químico na fonte (Armstrong-Altrin et al., 2015), sendo que valores baixos $(<3)$ indicam forte atuação do intemperismo químico. As amostras da Formação Corumbataí que possuem os maiores valores de CIA (> 70) possuem em geral as maiores razões $\mathrm{Al}_{2} \mathrm{O}_{3} / \mathrm{Na}_{2} \mathrm{O}$ (de 12,95 a 256,33), predominando valores entre 3 e 9, concordantes com a interpretação de intemperismo moderado.

Em relação aos elementos terras raras, as amostras da Formação Corumbataí, quando comparadas com os teores das médias mundiais para sedimentos NASC e PAAS, possuem conteúdos semelhantes $\left(\Sigma E_{\text {ETRASC }}=154,50\right.$, $\Sigma E_{\text {ETRAS }}=183,00, \Sigma$ ETR $_{\text {Fm Corumbataí }}=111,61$ - 380,16; média $=171,95)$. O padrão de distribuição de ETR da Formação Corumbataí, quando normalizados pela crosta continental superior (Rudnick e Gao, 2003) é sub- 
horizontal, mostrando leve empobrecimento em ETRL (elementos terras raras leves) em relação a ETRP (elementos terras raras pesados) $\left(\mathrm{La}_{(\mathrm{N}) / \mathrm{Lu}_{(\mathrm{N})}}=0,43-1,23, \mathrm{La}_{(\mathrm{N})} / \mathrm{Eu}_{(\mathrm{N})}=0,73-\right.$ $\left.1,28, \mathrm{Gd}_{(\mathrm{N})} / \mathrm{Lu}_{(\mathrm{N})}=0,66-1,29\right)$, com teores semelhantes à composição da crosta superior. Algumas amostras mostram fracas anomalias negativas de európio $\left(\mathrm{Eu}^{*}=0,78-0,99\right)$ (Figuras 9A, C, E).

Nos diagramas multielementares para HFSE (high field strength elements: $\mathrm{Ta}, \mathrm{Nb}, \mathrm{Hf}, \mathrm{Ti}$, Y), LILE (large-ion lithophile elements: Cs, $\mathrm{Rb}, \mathrm{Ba}, \mathrm{K}, \mathrm{Th}, \mathrm{U}, \mathrm{Sr}$ ), ETR e P, Sc, V, Cr, Co, $\mathrm{Ni}, \mathrm{Cu}, \mathrm{Zn}$ e $\mathrm{Ga}$, normalizados pela média da crosta superior (UCC, Rudnick e Gao, 2003)

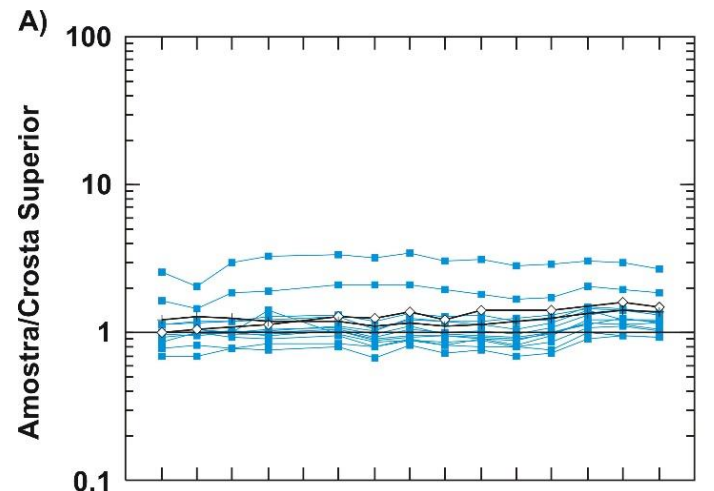

C)
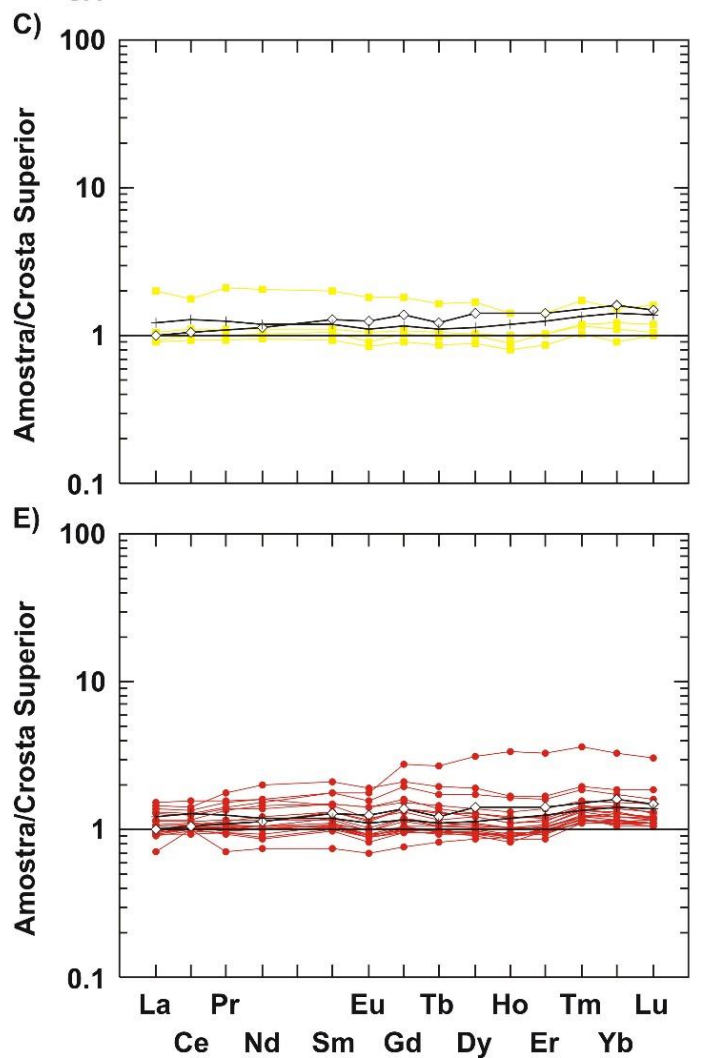

(Figura 9B, D, F), as amostras da Formação Corumbataí são comparadas com o padrão de distribuição do NASC e PAAS. O padrão de distribuição destes elementos mostra que os sedimentos da Formação Corumbataí são mais empobrecidos em $\mathrm{V}, \mathrm{Cr}, \mathrm{Co}, \mathrm{Ni}$ e $\mathrm{Cu}$ em relação à crosta superior e em relação ao NASC e ao PAAS. Os teores de $\mathrm{Ba}, \mathrm{K}, \mathrm{Th}, \mathrm{Ta}, \mathrm{Nb}, \mathrm{Y}$, $\mathrm{Zr}, \mathrm{Hf}, \mathrm{Ti}, \mathrm{Sc}, \mathrm{Zn}$ e Ga é semelhante. Os teores de Cs e Rb são mais elevados, e o teor de U é em parte mais alto, principalmente nas amostras do topo da sucessão. A distribuição de $\mathrm{Sr}$ é variável, parte das amostras mostram teores mais baixos e parte mais altos do que os valores de UCC, NASC e PAAS.

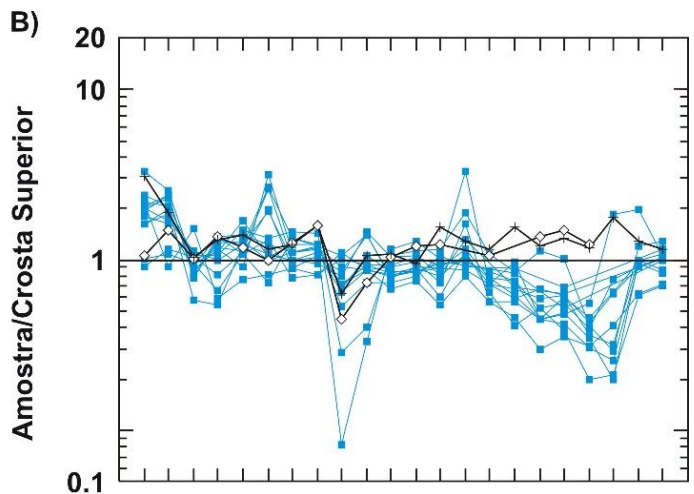

D)
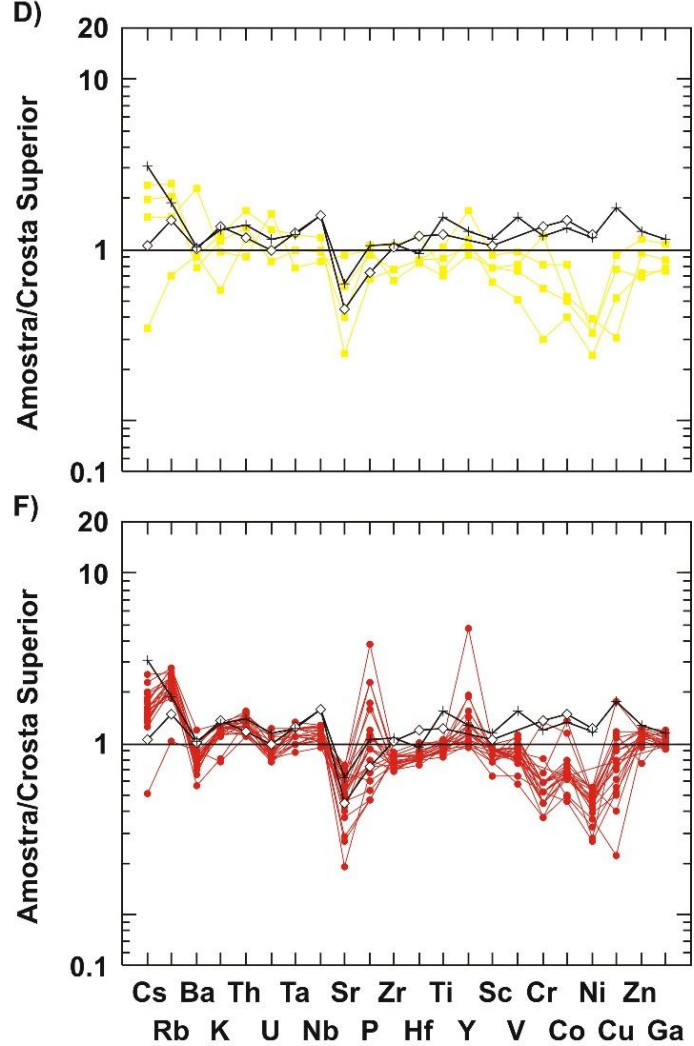

Figura 9. A), C), E) Padrão de distribuição de ETR normalizados pela crosta continental superior (Rudnick e Gao, 2003) para as amostras analisadas. B), D), F) Padrão de distribuição de elementos menores e traços e ETR normalizados pela crosta continental superior (Rudnick e Gao, 2003) para as amostras analisadas. Cruz: NASC; Losango: PAAS.

Círculos vermelhos: amostras da base da Formação Corumbataí; Quadrados amarelos: amostras da porção intermediária da Formação Corumbataí; Quadrados azuis: amostras do topo da Formação Corumbataí. 
Bhatia (1983) atesta que diagramas do tipo $\left(\mathrm{TiO}_{2}\right)$ versus $\left(\mathrm{Fe}_{2} \mathrm{O}_{3} \mathrm{~T}+\mathrm{MgO}\right),\left(\mathrm{Al}_{2} \mathrm{O}_{3} / \mathrm{SiO}_{2}\right)$ versus $\left(\mathrm{Fe}_{2} \mathrm{O}_{3 \mathrm{~T}}+\mathrm{MgO}\right),\left(\mathrm{K}_{2} \mathrm{O} / \mathrm{Na}_{2} \mathrm{O}\right)$ versus $\left(\mathrm{Fe}_{2} \mathrm{O}_{3 \mathrm{~T}}+\mathrm{MgO}\right)$ e $\left(\mathrm{Al}_{2} \mathrm{O}_{3}\right) /\left(\mathrm{CaO}+\mathrm{Na}_{2} \mathrm{O}\right)$ versus $\left(\mathrm{Fe}_{2} \mathrm{O}_{3 \mathrm{~T}}+\mathrm{MgO}\right)$ são eficientes para estabelecer correlação entre a composição geoquímica de arenitos e o contexto tectônico da bacia sedimentar na qual estão inseridos. Roser e Korsch (1986), entretanto, afirmam que, assim como arenitos provenientes de diferentes ambientes tectônicos de sedimentação possuem assinaturas geoquímicas características, estas características podem ser extrapoladas para sedimentos com tamanhos de grãos menores (siltitos e argilitos), definindo campos referentes a ambientes de margem passiva, margem continental ativa, e arcos de ilha oceânicos em um diagrama do tipo $\mathrm{K}_{2} \mathrm{O} / \mathrm{Na}_{2} \mathrm{O}$ versus $\mathrm{SiO}_{2}$ (Roser e Korsch, 1986). Segundo os diagramas propostos por Bhatia (1983) e por Roser e Korsch (1986), as amostras da Formação Corumbataí analisadas apresentam similaridades geoquímicas com sedimentos provenientes de arcos magmáticos (arcos de ilha continentais e margem continental ativa) (Figuras 10A, B, C, D, E). Bhatia (1983) também propõe o uso das funções discriminantes $\mathrm{F} 3 \quad(\mathrm{~F} 3=0,303-$ $0,0447 \mathrm{SiO}_{2}-0,972 \mathrm{TiO}_{2}+0,008 \mathrm{Al}_{2} \mathrm{O}_{3}-$ $0,267 \mathrm{Fe}_{2} \mathrm{O}_{3}+0,208 \mathrm{FeO}-3,082 \mathrm{MnO}+$ $0,14 \mathrm{MgO}+0,195 \mathrm{CaO}+0,719 \mathrm{Na}_{2} \mathrm{O}-$ $\left.0,032 \mathrm{~K}_{2} \mathrm{O}+7,51 \mathrm{P}_{2} \mathrm{O}_{5}\right)$ versus $\mathrm{F} 4(\mathrm{~F} 4=43,57-$ $0,421 \mathrm{SiO}_{2}+1,988 \mathrm{TiO}_{2}-0,526 \mathrm{Al}_{2} \mathrm{O}_{3}-$ $0,551 \mathrm{Fe}_{2} \mathrm{O}_{3}-1,61 \mathrm{FeO}+2,72 \mathrm{MnO}+$ $0,881 \mathrm{MgO}-0,907 \mathrm{CaO}-0,177 \mathrm{Na}_{2} \mathrm{O}-$ $1,84 \mathrm{~K}_{2} \mathrm{O}+7,244 \mathrm{P}_{2} \mathrm{O}_{5}$ ) para a determinação do ambiente tectônico associado à sedimentação, modificadas posteriormente por Roser e Korsch (1988). No diagrama F3 versus F4, as amostras da Formação Corumbataí encontram-se predominantemente distribuídas no campo das rochas depositadas em margem passiva (Figura $10 \mathrm{~F})$.

Bhatia e Crook (1986), por sua vez, propuseram a utilização de diagramas binários do tipo Ti/Zr versus $\mathrm{La} / \mathrm{Sc}$ e $\mathrm{La} / \mathrm{Y}$ versus $\mathrm{Sc} / \mathrm{Cr}$, e de diagramas ternários do tipo La-Th-Sc, Th$\mathrm{Co}-\mathrm{Zr} / 10$ e Th-Sc-Zr/10 como ferramentas para caracterizar a proveniência de sedimentos e para ajudar a determinar a natureza da margem continental ou da bacia oceânica. A utilização destes diagramas para as amostras analisadas sugere predominantemente composições semelhantes às de rochas formadas em arcos magmáticos (Figuras 10G, H, I, J, K).

McLennan et al. (1993) discute a utilização de diagramas do tipo $\mathrm{Th} / \mathrm{Sc}$ versus $\mathrm{Zr} / \mathrm{Sc}$ para avaliar o papel da concentração de minerais pesados durante a seleção sedimentar. As amostras da Formação Corumbataí, no diagrama $\mathrm{Th} / \mathrm{Sc}$ versus $\mathrm{Zr} / \mathrm{Sc}$ (Figura 11A, B), concentram-se no limite proposto por McLennan et al. (1993) para a mudança de uma tendência de variação composicional da rocha fonte dos sedimentos, relacionada com processos ígneos e o início de um processo de reciclagem sedimentar. As amostras da Formação Corumbataí apresentam razões Th/U entre 0,82 e 7,09, predominando valores acima de 4,36 (média de 4,50), e razões $\mathrm{Zr} / \mathrm{Sc}$ entre 3,15 e 22,88 , predominando valores acima de 10,32 (média de 13,61). Segundo McLennan et al. (1993), rochas sedimentares com razões $\mathrm{Zr} / \mathrm{Sc}>10$ e $\mathrm{Th} / \mathrm{U}>4$ indicam uma fonte submetida a forte intemperismo ou reciclagem de sedimentos (Figura 11C, D). Spalletti et al. (2012) consideram que o enriquecimento em Th e $\mathrm{Zr}$ é típico de rochas da crosta superior, e o $\mathrm{Zr}$ se concentra devido à reciclagem em relação a outros elementos mais móveis. As amostras da base e da porção intermediária da Formação Corumbataí tendem a manter um trend composicional subparalelo à variação composicional de rochas ígneas, enquanto as amostras do topo da formação fogem levemente deste trend, o que pode ser interpretado como uma pequena variação composicional da proveniência, ou maior susceptibilidade destes sedimentos aos processos de seleção e reciclagem sedimentar. Da mesma forma, amostras da base da Formação Corumbataí tendem a apresentar maiores razões $\mathrm{Th} / \mathrm{U}$ do que amostras do topo desta formação, o que pode indicar variação na atuação dos processos de seleção e reciclagem ao longo da deposição desta unidade, ou diferenças nas condições de intemperismo da área fonte. 
A)

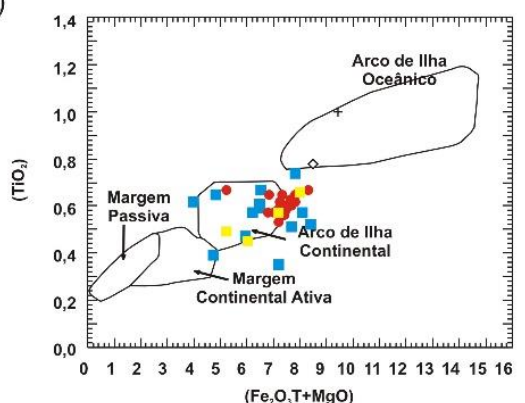

D)

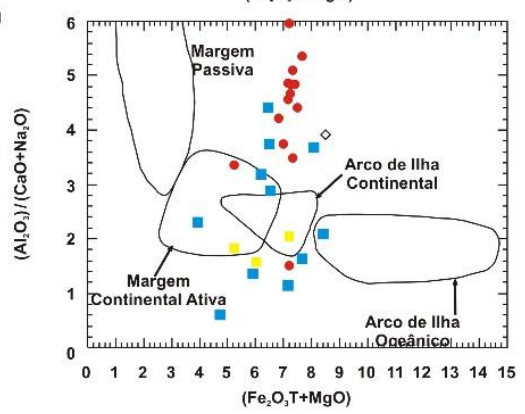

G)

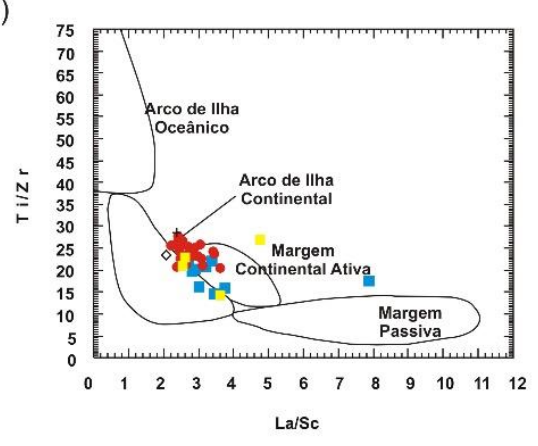

H)

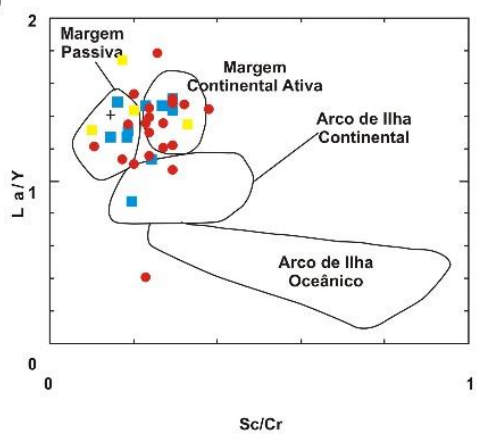

E)

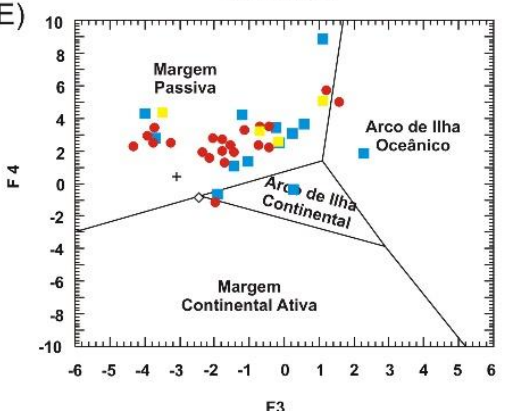

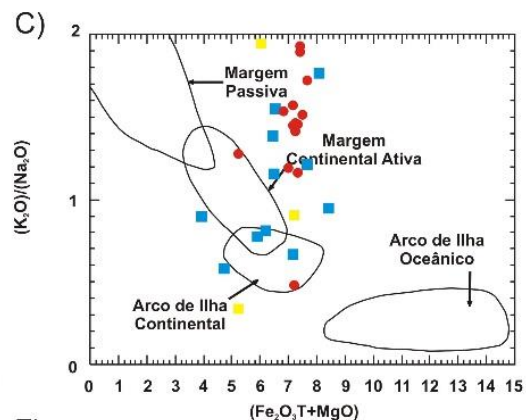

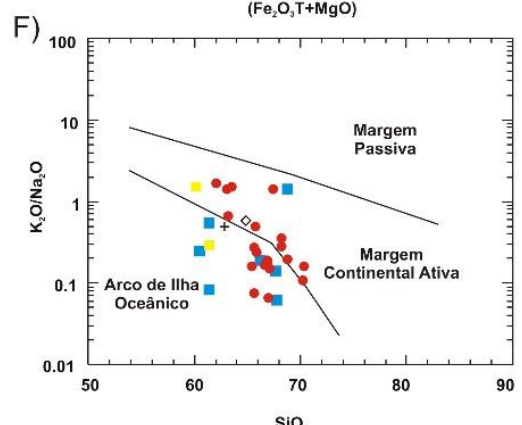

1)

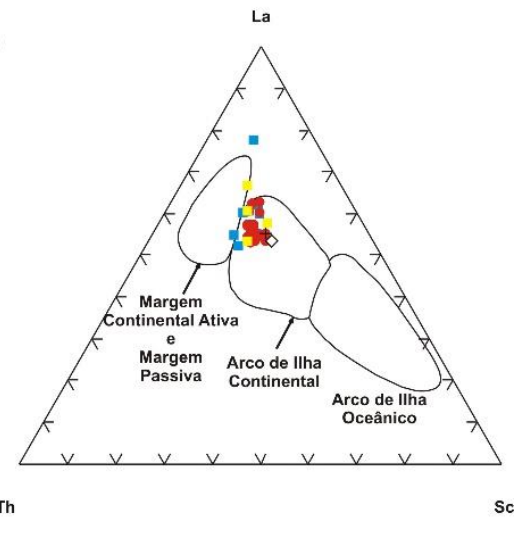

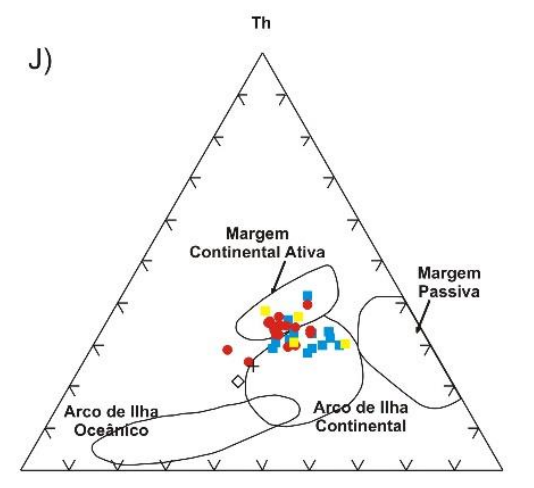

Figura 10. Diagramas discriminantes para as rochas analisadas. A), B), C), D) Bhatia (1983); E) Roser e Korsch

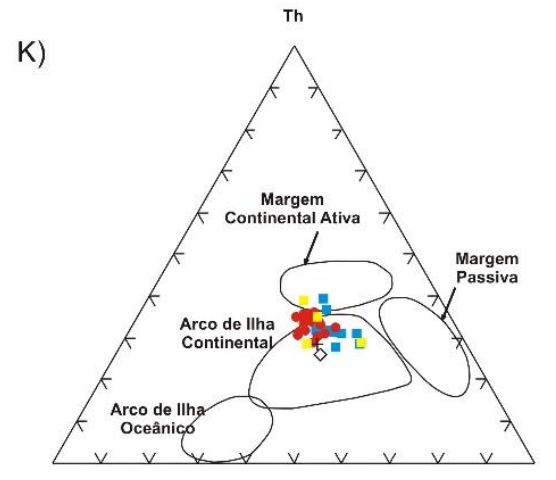

Zri10 (1988); F) Roser e Korsch (1986); G), H), I), J), K) Bhatia e Crook (1986). Cruz: NASC; Losango: PAAS. Círculos vermelhos: amostras da base da Formação Corumbataí; Quadrados amarelos: amostras da porção intermediária da Formação Corumbataí; Quadrados azuis: amostras do topo da Formação Corumbataí. 

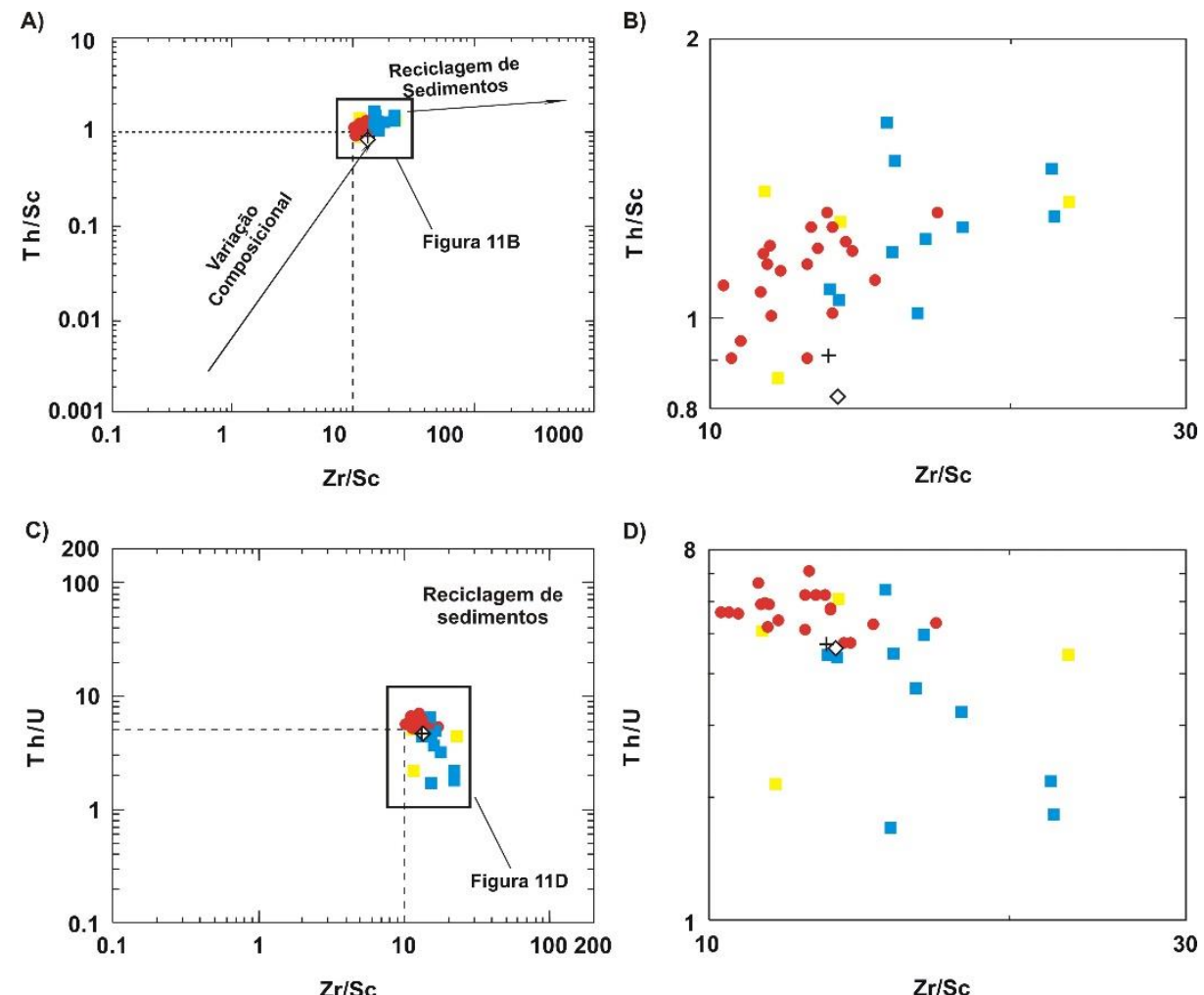

Figura 11. Diagrama $\mathrm{Th} / \mathrm{Sc}$ vs $\mathrm{Zr} / \mathrm{Sc}$ e $\mathrm{Th} / \mathrm{U}$ vs $\mathrm{Zr} / \mathrm{Sc}$ (modificado McLennan et al., 1993) das amostras analisadas. Cruz: NASC; Losango: PAAS; Círculos vermelhos: amostras da base da Formação Corumbataí; Quadrados amarelos: amostras da porção intermediária da Formação Corumbataí; Quadrados azuis: amostras do topo da Formação

Corumbataí.

\section{CONCLUSÕES E CONSIDERAÇÕES FINAIS}

Os dados geoquímicos analisados sugerem que a Formação Corumbataí, constituinte de uma bacia intracratônica, teve como área fonte um conjunto de rochas sedimentares quartzosas e ígneas félsicas, estabelecidas em clima tropical a subtropical, entretanto com remoção de sílica e álcalis ineficiente, resultando em argilominerais predominantemente illíticos e na preservação parcial dos feldspatos. Esta situação sugere intemperismo moderado das rochas que deram origem a esta sucessão sedimentar, embora haja evidências de atuação diferencial dos processos intempéricos ao longo da deposição da seção analisada, dadas principalmente pelas razões $\mathrm{Th} / \mathrm{U}$ das amostras da base e do topo da Formação. Entretanto, parte dos feldspatos presentes nas rochas analisadas é neoformada, decorrente do processo diagenético ou de alteração hidrotermal, resultando em plagioclásio sódico (albita). Uma vez que argilominerais illíticos não comportam elevados teores de $\mathrm{Na}^{+}$na estrutura, provavelmente parte do sódio necessário para a neoformação de albita foi fornecido durante a sedimentação, na forma de sais de sódio. Sendo assim, os processos intempéricos atuantes na fonte podem ter sido mais intensos, porém os teores de $\mathrm{Na}_{2} \mathrm{O}$ e $\mathrm{Al}_{2} \mathrm{O}_{3}$ podem ter sido modificados pela presença de componentes de precipitação química, modificados pelos processos hidrotermais decorrentes das intrusões que deram origem à Formação Serra Geral, resultando em padrões geoquímicos que refletem razões modificadas, o que pode levar a subestimar o efeito dos processos intempéricos. As rochas fontes desta sucessão sedimentar apresentam características geoquímicas semelhantes a arcos magmáticos, predominado características de arcos de ilhas continentais, sugerindo que os sedimentos que deram origem à Formação Corumbataí foram derivados de rochas félsicas formadas em arcos magmáticos e sequências sedimentares associadas, erodidas e depositadas em ambiente tectonicamente quiescente (bacia intracratônica), sujeitos a processos de reciclagem sedimentar. 


\section{AGRADECIMENTOS}

Os autores agradecem ao fomento fornecido pela FAPESP (projetos $\mathrm{n}^{\circ}$ 03/01123-7 e 2005/03683-5) e CNPQ (projetos no 301216/2008-8, nº 304535/2011-7 e no 576441/2008-2).

\section{BIBLIOGRAFIA}

1. ALMEIDA, F. F. M.; BARBOSA, O. Geologia das quadrículas de Piracicaba e Rio Claro. Boletim Divisão de Geologia e Mineralogia - Departamento Nacional de Produção Mineral, Rio de Janeiro, v. 143, p. 1-97, 1953. 2. ARMSTRONG-ALTRIN, J. S.; MACHAINCASTILLO, M. L.; ROSALES-HOZ, L.; CARRANZAEDWARDS, A.; SANCHEZ-CABEZA, J. A.; RUÍZFERNÁNDEZ, A. C. Provenance and depositional history of continental slope sediments in the Southwestern Gulf of Mexico unraveled by geochemical analysis. Continental Shelf Research, 2015. , v. 95, 1526, 2015.

3. ARMSTRONG-ALTRIN, J.S. Provenance of sands from Cazones, Acapulco, and Bahía Kino beaches, Mexíco. Rev. Mex. Cienc. Geol. 26 (3) 764-782. 2009.

4. ARMSTRONG-ALTRIN, J.S.; VERMA, S.P. Critical evaluation of six tectonic setting discrimination diagrams using geochemical data of Neogene sediments from known tectonic settings. Sediment. Geol. 177, 115129. 2005

5. BAKKIARAJ, D., NAGENDRA, R., NAGARAJAN, R., ARMSTRONG-ALTRIN, J.S. Geochemistry of sandstones from the Upper Cretaceous Sillakkudi Formation, Cauvery Basin, southern India: implication for provenance. J. Geol. Soc. India 76, 453467. 2010.

6. BARBOSA, O.; GOMES, F. A. Pesquisa de petróleo na Bacia do Rio Corumbataí, Estado de São Paulo. Boletim da Divisão de Geologia e Minas - DNPM, Rio de Janeiro, n.171, p.1-40, 1958.

7. BHATIA, M. R. Plate tectonics and geochemical composition of sandstones. The Journal Of Geology, Chicago, v. 91, n. 6, p.611-627, 1983.

8. BHATIA, M. R. Rare earth element geochemistry of Australian Paleozoic graywackes and mudrocks: provenance and tectonic control. Sedimentary Geology, v. 45, p. 97-113, 1985.

9. BHATIA, M. R.; CROOK, K. A. W. Trace element characteristics of graywackes and tectonic setting discrimination of sedimentary basins. Contributions to Mineralogy and Petrology, Springer-Verlag, v. 92, p.181193, 1986.

10. COX, R.; LOWE, D. R.; CULlERS, R. L. The influence of sediment recycling and basement composition on evolution of mudrock chemistry in the southwestern United States. Geochimica et Cosmochimica Acta, v. 59, n. 14, p. 2919-2940, 1995.

11. CULLERS, R.L. Implications of elemental concentrations for provenance, redox conditions, and metamorphic studies of shales and limestones near Pueblo, CO, USA. Chem. Geol. 191, 305-327. 2002.

12. CULLERS, R.L. The geochemistry of shales, siltstones and sandstones of Pennsylvanian - Permian age, Colorado, USA: implications for provenance and metamorphic studies. Lithos 51, 181-203. 2000.

13. DYPVIK, H. Mineralogy and geochemistry of the Mesozoic sediments of Andøya, northern Norway. Sedimentary Geology, v. 24, p. 45-67. 1979.

14. ETEMAD-SAEED, N., HOSSEINI-BARZI, M., ARMSTRONG-ALTRIN, J.S. Petrography and geochemistry of clastic sedimentary rocks as evidence for provenance of the Lower Cambrian Lalun Formation, Posht-ebadam block, Central Iran. J. Afr. Earth Sci. 61, 142-159. 2011.

15. FATIMA, S., KHAN, M.S. Petrographic and geochemical characteristics of Mesoproterozoic Kumbalgarh clastic rocks, NW Indian shield: implications for provenance, tectonic setting, and crustal evolution. Int. Geol. Rev. 54 (10) 1113-1144. 2012.

16. FU, X., WANG, J., ZENG, Y., TAN, F., FENG, X. REE geochemistry of marine oil shale from the Changshe Mountain area, northern Tibet, China. Int. J. Coal Geol. 81, 191-199. 2010.

17. GAMA JR, E. A sedimentação do Grupo Passa Dois (exclusive Formação Irati) - um modelo geomórfico. Revista Brasileira de Geociências, São Paulo, v. 9, n. 1, p. 1-16, 1979.

18. GROMET, L.P.; DYMEK, R.F.; HASKIN, L.A.; KOROTEV, R.L. The "North American Shale Composite": its compilation, major and trace element characteristics. Geochimica et Cosmochimica Acta, v. 48, p.2469-2482, 1984.

19. GUO, Q.; XIAO, W.; WINDLEY, B. F.; MAO, Q.; HAN, C.; QU, J.; AO, S.; LI, J.; SONG, D.; YONG, Y. Provenance and tectonic settings of Permian turbidites from the Beishan Mountains, NW China: implications for the Late Paleozoic accretionary tectonics of the Southern Altaids. Journal of Asian Earth Sciences 49, p. 54-68, 2011.

20. HACHIRO, J. O Subgrupo Irati (Neopermiano) da Bacia do Paraná. São Paulo, 1996. 182p. Tese (Doutorado em Geologia) - Instituto de Geociências, Universidade de São Paulo.

21. HASKIN, L. A.; FREY, F. A. Dispersed and NotSo-Rare Earths. The relative abundances of these elements reflect the earth's geochemical evolution from primordial matter. Science, v. 152(3720), p. 299-314. 1966.

22. HASKIN, M. A.; HASKIN L. A. Rare earths in European shales: A redetermination. Science, v. 154, p. 507-509. 1966.

23. HASUI, Y.; CARNEIRO, C. D. R.; ALMEIDA, F. F. M.; BARTORELli, A. (Org.). GEOLOGIA DO BRASIL. São Paulo: Beca, 2012. 900 p.

24. HERRON, M. M. Geochemical Classification of terrigenous sands and shales from core or log data. 
Journal of Sedimentary Petrology, Boulder, v. 58, p.820829, 1988.

25. HOSSAIN, H. M. Z.; ROSER, B. P.; J. -I. KIMURA. Petrography and whole-rock geochemistry of the Tertiary Sylhet succession, northeastern Bengal Basin, Bangladesh: Provenance and source area weathering. Sedimentary Geology, v. 228, p. 171-183, 2010.

26. JORGE, R. C. G. S.; FERNANDES, P.; RODRIGUES, B.; PEREIRA, Z.; OLIVEIRA, J. T. Geochemistry and provenance of the Carboniferous Baixo Alentejo Flysch Group, South Portuguese Zone. Sedimentary Geology, v. 284-285, p. 133-148. 2013.

27. LACERDA FILHO, J. V. de, REZENDE, A., SILVA, A. Programa de Levantamentos Geológicos Básicos do Brasil - Geologia e Recursos Minerais do Estado de Goiás e Distrito Federal. 1:500.000. 2o edição. Goiânia: conv. CPRM - Seperintendência Regional de Goiânia/METAGO S.A./UnB. 217 p. 1999.

28. LACERDA FILHO, J. W.; Abreu Filho, W.; Valente, C. R.; Oliveira, C. C.; Albuquerque, M. C. Geologia e Recursos Minerais do Estado de Mato Grosso. Programa Integração, Atualização e Difusão de Dados de Geologia do Brasil. Convênio CPRM/SICMEMT, MME, 235 p., 2004.

29. LANDIM, P. M. B. O Grupo Passa Dois (P) na Bacia do Rio Corumbataí (SP). Boletim. Divisão Geologia e Mineralogia/DNPM, São Paulo, v. 252, 103 p., 1970.

30. LEE, T. II. Geochemistry of shales of the Upper Cretaceous Hayang Group, SE Korea: Implications for provenance and source weathering at an active continental margin. Sedimentary Geology, v. 215, p. 112. 2009.

31. McLENNAN, S. M.; TAYLOR, S. R. Geochemical standards for sedimentary rocks: trace-element data for U.S.G.S. standards SCo-1, MAG-1 and SGR-1. Chemical Geology, v. 29, p. 333-343. 1980.

32. McLENNAN, S. M.; HEMMING, S.; MCDANIEL, D. K.; HANSON, G. N. Geochemical approaches to sedimentation, provenance, and tectonics. Geological Society of America, Special Paper 284, 1993.

33. MELO, M. S. A. Formação Rio Claro e depósitos associados: sedimentação neocenozóica da Depressão Periférica Paulista. São Paulo, 1995, 144p. Tese (Doutorado em Geociências) - Instituto de Geociências, Universidade de São Paulo.

34. MENDES, J. C. A Formação Corumbataí na região do Rio Corumbataí: Estratigrafia e descrição dos lamelibrânquios. Boletim da Faculdade de Filosofia, Ciências e Letras da Universidade de São Paulo, São Paulo, n.145 (Geologia 8), p.1-119, 1952.

35. MEZZALIRA, S. (coord.). Léxico Estratigráfico do estado de São Paulo. Boletim do IG, 5. São Paulo, Instituto Geológico, 1981.

36. MILANI, E. J. Evolução tectono-estratigráfica da Bacia do Paraná e o seu relacionamento com a geodinâmica fanerozóica do Gondwana Sul-ocidental. Porto Alegre, 1997, 255 p. Tese (Doutorado) - Instituto de Geociências, Universidade Federal do Rio Grande do Sul.

37. MILANI, E. J.; MELO, J. H. G.; SOUZA, P. A.; FERNANDES, L. A.; FRANÇA, A. B. Bacia do Paraná.
Boletim de Geociências da Petrobrás, v. 15, n. 2, p. 265287, 2007.

38. MORADI, A. V.; SARI, A.; AKKAYA, P. Geochemistry of the Miocene oil shale (Hançili Formation) in the Çankırı-Çorum Basin, Central Turkey: Implications for Paleoclimate conditions, source-area weathering, provenance and tectonic setting. Sedimentary Geology, 2016 (in press).

39. NESBITT, H. W.; YOUNG, G. M. Early Proterozoic climate sand plate motions inferred from major element chemistry of lutites. Nature, 299,715-717, 1982.

40. PEARCE, T. J.; BESLYB, B. M.; WRAY, D. S.; WRIGHT, D. K. Chemostratigraphy: a method to improve interwell correlation in barren sequences - a case study using onshore Duckmantian/Stephanian sequences (West Midlands, U.K.). Sedimentary Geology, v. 124, p. 197-220. 1999.

41. PE-PIPER, G.; TRIANTAFYLLIDIS, S.; PIPER, D. J. W. Geochemical identification of clastic sediment provenance from known sources of similar geology: the Cretaceous Scotian Basin, Canada. Journal of Sedimentary Research 78, p. 595-607, 2008.

42. PERROTTA, M. M.; SALVADOR, E. D.; LOPES, R. C.; D'AGOSTINO, L. Z.; PERUFFO, N.; GOMES, S. D.; SACHS, L. L. B.; MEIRA, V. T.; GARCIA, M. G. M.; LACERDA FILHO, J. V. 2005. Mapa Geológico do Estado de São Paulo, Escala: 750.000. Programa Geologia do Brasil - PGB, Companhia de Pesquisa de Recursos Minerais (CPRM) - Serviço Geológico do Brasil, São Paulo.

43. PETRELli, M.; POLI, G.; PERUGINI, D.; PECCERILLO, A. Petrograph: a new software to visualize, model, and present geochemical data in igneous petrology. Geochemistry, Geophysics, Geosystems, Wiley Online Library, v. 6, n. 7, p.1-15, jul. 2005. DOI 10.1029/2005GC000932. Disponível em: <http://onlinelibrary.wiley.com/doi/10.1029/2005GC000 932/pdf>. Acesso em: 15 ago. 2013.

44. PETRI, S.; COIMBRA, A. M. Estruturas sedimentares das formações Irati e Estrada Nova (Permiano) e sua contribuição para a elucidação dos seus paleoambientes geradores, Brasil. In: CONGRESO LATINO-AMERICANO DE GEOLOGIA, 5, 1982. Actas do V Congreso Latino-americano de Geologia, 1982, v. 2, p. 353-371.

45. PETRI, S.; FÚlFARO, V. J. Geologia do Brasil (Fanerozóico). São Paulo: USP, 1983. 631 p.

46. PETTIJOHN, F. J. Chemical composition of sandstones-excluding carbonate and volcanic sands. Geological Survey Professional Paper, v. 440-S, 1-19. 1963.

47. RAHMAN, M. J. J.; FAUPL, P. The composition of the subsurface Neogene shales of the Surma group from the Sylhet Trough, Bengal Basin, Bangladesh. Sedimentary Geology, v. 155, p. 407-417. 2003.

48. RAHMAN, M. J. J.; SHIGEYUKI SUZUKI, S. Geochemistry of sandstones from the Miocene Surma Group, Bengal Basin, Bangladesh: Implications for Provenance, tectonic setting and weathering. Geochemical Journal, v. 41, p. 415-428, 2007.

49. RAZA, M., AHMAD, A.H.M., KHAN, M.S., KHAN, F. Geochemistry and detrital modes of 
Proterozoic sedimentary rocks, Bayana Basin, north Delhi fold belt: implications for provenance and sourcearea weathering. Int. Geol. Rev. 54 (1) 111-129. 2012.

50. RICHARD, L. R. Mineralogical and Petrological Data Processing System. MINPET for Windows. Version 2.02. Copyright 1988-1995.

51. ROHN, R. Evolução ambiental da Bacia do Paraná durante o Neopermiano no leste de Santa Catarina e do Paraná. São Paulo, 1994, 386 p. Tese (Doutorado em Geologia Sedimentar) - Instituto de Geociências, Universidade de São Paulo.

52. ROHN, R. The Upper Permian of the Paraná Basin, Brazil: a new stratigraphic approach. Gaea Heidelbergensis, Heidelberg, v. 3, p.290-29, 1997.

53. ROLLINSON, H. R. Using Geochemical Data: Evaluation, Presentation, Interpretation. United Kingdom: Taylor Francis Ltd, 1993.

54. ROSER, B. P.; KORSCH, R. J. Determination of tectonic setting of sandstone-mudstone suites using $\mathrm{SiO} 2$ content and $\mathrm{K} 2 \mathrm{O} / \mathrm{Na} 2 \mathrm{O}$ ratio. Journal of Geology, v. 94, p. 635-50, 1986.

55. ROSER, B. P.; KORSCH, R. J. Provenance signatures of sandstone-mudstone suites determined using discriminant function analysis of major-element data. Chemical Geology, v. 67, p. 119-139, 1988.

56. RUDNICK, R. L.; GAO, S. Composition of the continental crust. In: RUDNICK, R. L. (ed.). The Crust. Amsterdam: Elsevier, 2003, p. 1-70.

57. RYAN, K. M., WILliAMS, D. M. Testing the reliability of discrimination diagrams for determining the tectonic depositional environment of ancient sedimentar basins. Chemical Geology, 242, p. 103-125, 2007.

58. SCHNEIDER, R. L.; MÜLMANN, H.; TOMMASI, E.; MEDEIROS, R. A.; DAEMON, R. F.; NOGUEIRA, A. A. Revisão estratigráfica da Bacia do Paraná. In: CONGRESSO BRASILEIRO DE GEOLOGIA, 28, 1974, Porto Alegre. Anais... Porto Alegre: Sociedade Brasileira de Geologia, 1974, v.1, p. 41-65.

59. SELVARAJ, K.; CHEN, C.-T.A. Moderate chemical weathering of subtropical Taiwan: Constraints from solid-phase geochemistry of sediments and sedimentary rocks. J. Geol. 114 (1) 101-116. 2006.

60. SOARES, P. C.; LANDIM, P. M. B. Aspectos regionais da estratigrafia da Bacia do Paraná no seu flanco nordeste. In: CONGRESSO BRASILEIRO DE GEOLOGIA, 27, 1973, Aracaju. Anais... Aracaju: Sociedade Brasileira de Geologia, 1973, v. 1, p. 243-256. 61. SOUSA, M. O. L. Evolução tectônica dos altos estruturais de Pitanga, Artemis, Pau D'Alho e Jibóia Centro do Estado de São Paulo. Rio Claro, 2002, 206p. Tese (Doutorado em Geologia Regional) - Instituto de Geociências e Ciências Exatas, Universidade Estadual Paulista.

62. SOUZA, S. H. M. Fácies sedimentares das Formações Estrada Nova e Corumbataí no Estado de São
Paulo. São Paulo, 1985, 142 p. Dissertação (Mestrado em Geologia Sedimentar) - Instituto de Geociências, Universidade de São Paulo.

63. SPALLETTI, L. A.; LIMARINO, C. O.; PIÑOL, F. C. Petrology and geochemistry of Carboniferous siliciclastics from the Argentine Frontal Cordillera: A test of methods for interpreting provenance and tectonic setting. Journal of South American Earth Sciences, v.36, p. 32-54.

64. SuguiO, K.; SOUZA, S. H. M. Restos de mesossauridios da Formação Corumbataí, Permiano da Bacia do Paraná, no Estado de São Paulo. Anais da Academia Brasileira de Ciências, v. 57, n. 3, p. 339-347, 1985.

65. TAYLOR, S. R.; MCLENNAN, S. M. The composition and evolution of the continental crust: rare earth element evidence from sedimentary rocks. Philosophical Transactions of The Royal Society A, Londres, v. 301, p.381-399, 1981.

66. VERMA, S. P.; ARMSTRONG-ALTRIN, J. S. Geochemical discrimination of siliciclastic sediments from active and passive margin settings. Sedimentary Geology, p. 332, 1-12, 2016.

67. VON EYNATTEN, H.; DUNKL, I. Assessing the sediment factory: the role of single grain analysis. EarthScience Reviews, 115, p. 97-120, 2012.

68. WELTJE, G. J. Quantitative models of sediment generation and provenance: state of the art and future developments. Sedimentary Geology 280, p. 4-20, 2012. 69. WELTJE, G. J. Ternary sandstone composition and provenance: an evaluation of the Dickinson Model. In: Buccianti, A., Mateu-Figueras, G., Pawlowsky-Glahn, V. (Eds.): Compositional Data Analysis in the Geosciences: From Theory to Practice. Geological Society, London, 2006, p. 79-99, Special Publications No. 264.

70. ZAID, S.M. Provenance, diagenesis, tectonic setting and geochemistry of Rudies sandstone (Lower Miocene), Warda Field, Gulf of Suez, Egypt. J. Afr. Earth Sci. 667, 56-71. 2012.

71. ZAINE, J. E. Mapeamento Geológico - Geotécnico por meio do detalhamento progressivo: ensaio de aplicação na área urbana do município de Rio Claro (SP). Rio Claro, 2000, 120p. Tese (Doutorado em Geociências) - Instituto de Geociências e Ciências Exatas, Universidade Estadual Paulista.

72. ZANARDO, A.; MORENO, M. M. T.; MONTIBELLER, C. C.; ROCHA, R. R.; ROVERI, C. D.; AZZI, A. A.; NAVARRO, G. R. B. Formação Corumbataí na região de Rio claro/SP: estratigrafia, petrografia e implicações genéticas. Revista Geociências, Rio Claro, 2016. in press.

Manuscrito recebido em: 29 de Julho de 2015 Revisado e Aceito em: 29 de Setembro de 2016 